Portland State University

PDXScholar

Spring 7-10-2017

\title{
Intestinal Microbiota Diversity of Pre-Smolt Steelhead (Oncorhynchus mykiss) Across Six Oregon and Washington Hatcheries
}

Christina Carrell Yildirimer

Portland State University

Follow this and additional works at: https://pdxscholar.library.pdx.edu/open_access_etds

Part of the Animal Sciences Commons, Biology Commons, and the Microbiology Commons Let us know how access to this document benefits you.

\section{Recommended Citation}

Yildirimer, Christina Carrell, "Intestinal Microbiota Diversity of Pre-Smolt Steelhead (Oncorhynchus mykiss) Across Six Oregon and Washington Hatcheries" (2017). Dissertations and Theses. Paper 3709.

https://doi.org/10.15760/etd.5593

This Thesis is brought to you for free and open access. It has been accepted for inclusion in Dissertations and Theses by an authorized administrator of PDXScholar. Please contact us if we can make this document more accessible: pdxscholar@pdx.edu. 
Intestinal Microbiota Diversity of Pre-Smolt Steelhead (Oncorhynchus mykiss) Across Six Oregon and Washington Hatcheries

\title{
by
}

\section{Christina Carrell Yildirimer}

A thesis submitted in partial fulfillment of the requirements for the degree of

\author{
Master of Science \\ in \\ Biology \\ Thesis Committee: \\ Kim H. Brown, Chair \\ Rahul Raghavan \\ Suzanne Estes
}

Portland State University

2017 


\begin{abstract}
The Pacific Northwest is known for its once-abundant wild salmonid populations that have been in decline for more than 50 years due to habitat destruction and commercial overexploitation. To compensate, federal and state agencies annually release hundreds of thousands of hatchery-reared fish into the
\end{abstract} wild. However, accumulating data indicate that hatchery fish have lower fitness in natural environments, and that hatchery rearing negatively influences return rates of anadromous salmonids. Recently, mounting evidence revealed that the richness and diversity of intestinal microbial species influence host health. We examined the gut microbiota of pre-migratory hatchery-reared steelhead (Oncorhynchus mykiss) to assess microbial community diversity. The Cascade Mountains serve as an allopatric border between two distinct clades of steelhead that show significant differences in genomic and mitochondrial diversity. We identified differences in core microbiota of hatchery-reared fish that correlate with this divergent phylogeographic distribution. Steelhead sampled from hatcheries east of the Cascades had overall greater core gut microbiota diversity. These differences were found despite similarities in diet and rearing conditions.

In addition to taxonomic variation across the geographic divide, we identified significant differences in metabolic pathways using PICRUSt gene 
prediction software. Our analysis revealed significant enrichment of genes associated with lipid metabolism in the gut microbiome of western fish. 8 of 19 individual lipid metabolism pathways were more prominent in western populations. Lipids are a vital nutritional component for teleost species involved in migration and subsequent return for spawning in natal environments. We hypothesize that the observed differences in lipid metabolism across this phylogenetic divide results from an increased ability of eastern Cascade (O. $\mathrm{m}$. gairdneri) fish to utilize lipids taken in via the diet. This increased absorption and utilization would make lipids less available for the intestinal microbiota of the eastern fish, as evidenced by the lower abundance of lipid metabolism genes in the east. Our research utilizes information from the microbiome to understand the phenotypic implications occurring in segregated populations of hatchery-reared steelhead, further confirming elements of coevolution between an organism and its internal environment. 


\section{Dedication}

This thesis is dedicated to my family and especially to my partner, Tim.

Their love and support during this journey has meant the world to me.

I also would like to dedicate this work to my students past and future, you are an inspiration. And to my big sister Leslie, who wanted to be an astronaut and grow plants on the moon. 


\section{Acknowledgements}

I would like to thank Kim Brown for allowing me the opportunity to work in his lab here at Portland State University and for his kindness and guidance throughout this work as well as the remainder of my committee Rahul Raghavan and Suzanne Estes. I also would like to offer a huge thank you to all hatchery contact persons who assisted me with sample collection: Craig Banner, Joe Holbert, Marc Garst, Clint Fitch and John Aleckson. It was a wonderful experience to visit hatcheries across Oregon and Washington and to experience their shared commitment and passion for sustaining hatchery stocks firsthand. I offer many thanks and much appreciation to my fellow graduate students, my lab mates Alicia Chivers, Josh Faber-Hammond and especially Lindsay A. Holden for the many questions she answered and her unwavering support and kindness. A special thanks goes out to the Biology department for offering me the opportunity to be a teaching assistant. I love teaching and hope to continue in the future. In addition, I could not have made it without the bioinformatics help of Brett Younginger and Annie Lindgren, who demystified the terminal interface and opened my eyes to its possibilities. 


\section{Table of Contents}

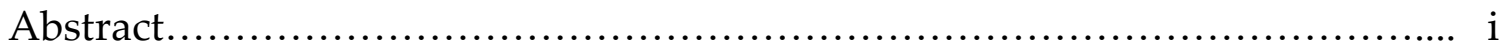

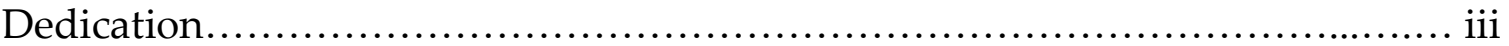

Acknowledgements......................................................... iv

List of Tables..................................................................... vi

List of Figures...........................................................

Chapter 1: Introduction.................................................. 1

1.1 Hatchery Environment and Salmonid Lifecycle...................... 2

1.2 Effects of Diet.......................................................... 9

1.3 Microbiota Effects on the Host.................................. 16

Chapter 2: Gut Microbiota Lipid Metabolism Varies Across Rainbow Trout (Oncorhyncus mykiss) Phylogenetic Divide......................... 21

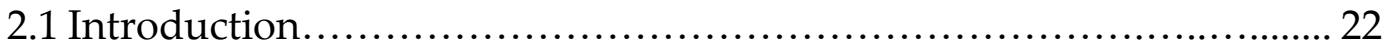

2.2 Materials and methods........................................ 29

2.3 Results............................................................. 40

2.4 Discussion........................................................ 43

Chapter 3: Conclusions.................................................. 51

References.............................................................. 71

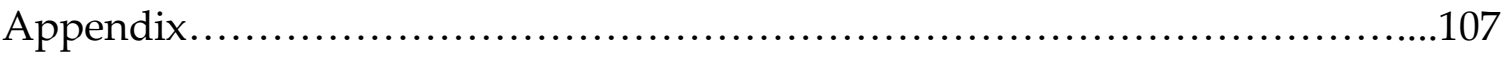




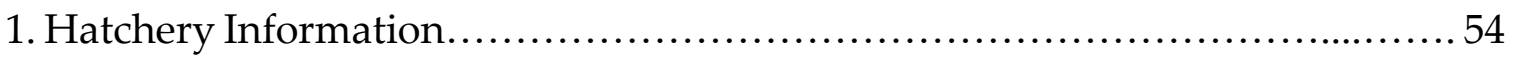

2. Primers used, V4 region of $16 \mathrm{~S}$ rDNA for Illumina MiSeq platform.................. 55

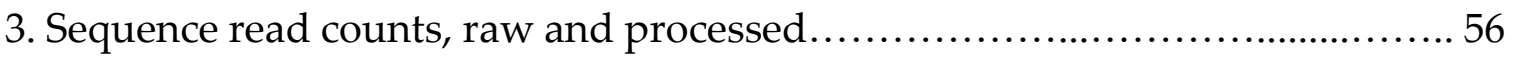

4. Counts of unique taxa present, per sample................................................. 57

5. Alpha diversity statistics, all observed OTUs............................. 58

6. Beta diversity statistics, all observed OTUs................................ 59

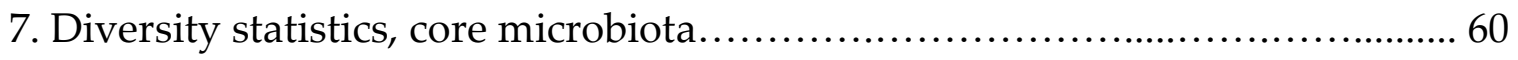

8. Table of core microbiota $(80 \%)$ constituents east................................. 61

9. Table of core microbiota $(80 \%)$ constituents west................................. 62 


\section{List of Figures}

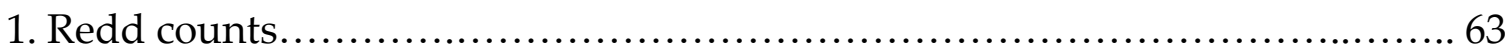

2. Native range of Oncorhynchus mykiss sub-species in Pacific Northwest......... 64

3. Rarefaction curves, all observed OTUs..................................... 65

4. Mean relative $\%$ sequence abundance of core microbiota shared between

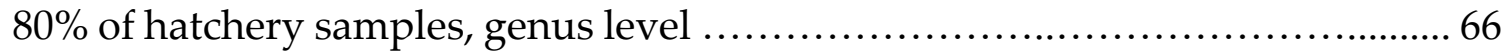

5. Core microbiota $(80 \%)$ bar charts, per sample............................... 67

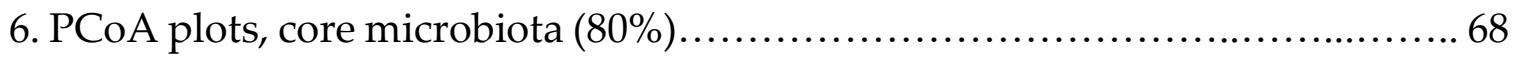

7. Extended error bar, KEGG level 2 significant sub-categories................... 69

8. Extended error bar, KEGG level 3 significant functional pathways.............. 70 
Chapter One

Introduction 


\subsection{Hatchery Environments and the Salmonid Lifecycle}

The Pacific Northwest (PNW) is well known for its populations of anadromous salmonid fish. Their once-abundant wild populations have been in dramatic decline since the 1950 's due to habitat destruction and commercial overexploitation (Figure 1). This ecological extinction caused by overfishing has decimated aquatic ecosystems and has preceded all other widespread human disturbance such as pollution, degradation of water quality, and anthropogenic climate change (Jackson et al., 2001). The decline in the PNW population of native anadromous fishes over the last one hundred years is due to this combination of factors.

The Salmonid lifecycle begins in freshwater streams and lakes where juveniles develop and mature until undergoing an arduous downstream journey to the ocean where they will spend 2-5 years as adults. When ready to reproduce, they return to their natal freshwater streams to spawn. These species are significant not only to the economy, but to the cultural identity of the Pacific Northwest, and many efforts have been undertaken to restore dwindling populations (Araki et al., 2007; Schmid and Araki, 2010). To compensate for continued declines, federal and state agencies annually release hundreds of 
thousands of hatchery-reared fish into the wild (i.e., hatchery stocking) to enhance fish populations for commercial, recreational, and conservation interests.

To support stockings, the National Fish Hatchery System (NFHS) was established by Congress in 1871 in an effort to conserve fishery resources for future generations and bring to light the anthropogenic threats posed to fisheries. The NFHS advanced a nationwide system of fish culture and propagation, which has evolved to become a network of hatcheries, laboratories and research centers. The mission of this network, which focuses on species listed as threatened or endangered, is to restore dwindling populations before they are listed using science-based fish and aquatic conservation techniques. The NFHS partners with states and federally recognized Native American tribes to help restore depleted native fish stocks lost due to human activity, including federal water development projects which are also called upon to participate in hatchery system funding. For example, the 2013 Strategic Hatchery and Workforce Planning Report put out by U.S. Fish and Wildlife Service indicates there were 291 national propagation programs focused on restoration of listed species, with a cost of nearly 11 million dollars (“National Fish Hatchery System," 2013).

Hatcheries are designed to produce large numbers of big fish, available to release for commercial and recreational use, as well as to aid in maintenance of 
wild fish populations (Araki et al., 2007; Brown et al., 2003). While this appears a logical solution to the problem of dwindling populations of wild salmonids, there is growing evidence that results of this practice are mixed. Return rates of hatchery fish are half those of wild fish (Chilcote, 2003; Schmid and Araki, 2010). Accumulating data also indicate that hatchery fish have lower fitness in natural environments compared to wild fish. Despite more than a hundred years of scientific study, the reasons for this discrepancy in return rates remains unclear (Araki et al., 2007), even as hatchery systems are lauded as enviable success stories by federal agencies and related commercial interests.

Hatchery reared salmonids encounter difficulties post-release that may impinge their success and subsequent return rates once time has come to spawn. Given their dependence on time released pellet feedings and lack of prior experience with live prey, hatchery fish have difficulty finding prey in the early stages of life post-release (Brown et al., 2003). These difficulties coincide with a critical period of time in the salmonid lifecycle, smoltification. Smoltification is a physiological transition modulated by the neuroendocrine system that anadromous fishes undergo to prepare for their transition from a relatively unproductive fresh water environment to the highly productive salt water found in the pelagic ecosystem. During smoltification, structural and functional 
transformations occur which involve independent yet coordinated developmental changes in the physiology, biochemistry, morphology and behavior of juvenile salmonids. Some examples include the silvering of the body to better shoal in pelagic environments, and improved salinity tolerance as juveniles move through estuaries on their way to the sea (Urke et al., 2010). This is the time when mortality rates for hatchery-raised salmonids are at the highest (Brown et al., 2003). Improving hatchery systems to better prepare juvenile fish for this difficult postrelease period is a common goal of both commercial and conservation interests.

A variety factors have been investigated relevant to post-release success for hatchery-reared fish. The length of fish when released has been shown to influence survival and enhance return rates of anadromous hatchery-reared salmonids (Beckman et al., 1999; Tipping, 1998). Return rates appeared to increase when release length was more than 190mm (Tipping, 1998). Yet size is not necessarily the determining factor of success in wild environments. It has also been found that over-summer survival for domesticated, or hatchery-raised, salmonids was consistently lower post-release than for the smaller wild fish of the same species living in the same river system (Schmid and Araki, 2010).

Domestication selection favors certain traits, physiological states, and/or sets of conditions for fish raised in captivity, which are less likely to be 
advantageous in the wild. Evidence from a number of studies indicates that genetic diversity and post-release viability is in fact reduced in hatchery stocks (Chilcote, 2003; Schmid and Araki, 2010). The major effects of hatchery rearing include lower survival, reduced genetic diversity and reproductive fitness, although few studies have provided any direct evidence of enhanced traits for wild stock (Schmid and Araki, 2010). Hatchery-raised fish can hinder the success of wild populations through genetic intermixing that occurs when wild and hatchery-raised fish interbreed, indicating a possible genetic component to reduced return rates (Chilcote, 2003; Miller et al., 2004). Genetics, however, is not the sole source of physiological differences between hatchery stock and wild fish living in nearby river systems. Why else might fish raised in hatchery environments have such difficulties during that critical period post-release?

Previous research highlights two significant areas, environment and diet, as sources of influence on the physiology and viability of hatchery stock postrelease. Narrowing down environmental factors relevant to success in the wild is difficult when the fish in question spends its life in both freshwater and pelagic ecosystems. A study conducted by The National Oceanic and Atmospheric Association (NOAA) in 2005 investigated the use of models to predict return rates for wild Chinook salmon. Results indicated that environmental conditions 
experienced during ocean residency, though difficult to quantify, accounted for only $5 \%$ of the variation in return rates, and that incorporating residency in freshwater habitats into the model was critical to understanding the role played by the environment (Greene et al., 2005). This work indicates that the effects of early life in a freshwater habitat is a key factor influencing return rates for Chinook salmon, and likely anadromous salmonids in general.

Hatchery stock reared in aquaculture environments experience vastly different living conditions (i.e., high density and increased competition) during their development than wild fish (Brown et al., 2003). Standard cement raceways, and less commonly gravel-bottomed ponds, are primary hatchery substrates; young hatchery stocks spend their life here before release into river systems. Success in post-release steelhead on the Cowlitz River in Oregon was shown to increase when fish were reared in gravel ponds over cement raceways (Tipping, 1998). Results concluded that ponds grew better quality fish than concrete raceways and that a contributing factor to that success was access to more natural foodstuffs in the pond. This access may have provided both nutritional advantages via ingestion of wild foods like insects and small crustaceans, and offered fish opportunities to learn important foraging behaviors required for a successful life post-release. Incorporation of these types of foodstuffs into the diets of hatchery- 
reared fish could assist in overcoming the difficulties experienced during the critical period of life spent in limnic environments.

Fish physiology is heavily influenced by diet. Hatchery systems are successful at growing abundant numbers of large juveniles well suited to a domestic environment. Hatchery stocks are typically fed processed fish meal pellets on a regular schedule, in a crowded environment with increased competition for resources from the thousands of fish that cohabitate in the same run or pond. One downside of this practice is that fishmeal is expensive; therefore much research has been undertaken to identify cost-effective alternatives that have only marginal impacts on fish health and physiology (Mansfield et al., 2010; Wong et al., 2013). For example, in 2005 the cost (U.S.) of one metric ton of fish meal was $\$ 600$, by 2010 that cost had risen to $\$ 2000$ (Sánchez-Muros et al., 2014). In addition, fish and soy meal production severely impact the environment. Fish meal production depends on the catch, which is quantitatively and qualitatively variable. It contributes to the "clearly unsustainable" deterioration of the marine environment by stripping fisheries, causing widespread disruption throughout the marine food chain (Barroso et al., 2014). Growing soy for feed necessitates deforestation of areas with high biological value, involves high consumption of water resources and utilizes large amounts of pesticides and fertilizers (Sánchez- 
Muros et al., 2014). Soy-based feed is commonly offered as an alternative to fish meal, yet some evidence has shown that high levels of intestinal inflammation occur in both salmon and steelhead when levels of soy in feed were too high (Mansfield et al., 2010). Differences in intestinal microbiota were also detected in fish receiving soymeal-based feed vs. fish meal (Mansfield et al., 2010; Storebakken et al., 2000), with a potential negative impact on development detected. Wild steelhead living in Pacific Northwest waterways forage on a variety of foodstuffs, including salmon eggs, small fish and zooplankton. They also ingest large quantities of arthropods, such as stonefly nymphs, caddis fly pupae, grasshoppers, snails and small crawdads (www.fisheries.noaa.gov, 2016).

\subsection{Effects of Diet}

It is here that the environment and diet of wild salmonids might converge with hatchery science to offer a unique alternative to the traditional hatchery diet of fishmeal or soymeal pellets; the incorporation of insect meal into hatchery fish feed. Including insect meal in hatchery fish feed might better mimic the diet of their wild counterparts and could alter their gut microbiota, possibly providing an advantage when ingesting wild foodstuffs post-release.

The evaluation of insect meal as an alternative feed source is a new and burgeoning field of research (Makkar et al., 2014; Rumpold and Schlüter, 2013). 
Like crustaceans, insects belong to the class of arthropods, and count more than a million species. Insects represent an innovative feed source rich in high quality protein, fats, minerals and vitamins (Rumpold and Schlüter, 2013). There are nearly 2000 species of insects in the world fit for human consumption (Huis et al., 2013), 69 of which are found in the United States. Makkar (2014) investigated five types of insects as an alternative feed source, including mealworms, grasshoppers, silkworm pupae, housefly maggots and black soldier fly larvae; they found that the crude protein content ranged from $42-63 \%$, with lipid content upwards of $36 \%$ in some insect species. Soy and fish meals range from $50-73 \%$ crude protein and 3-9\% fats respectively (Barroso et al., 2014). Insect meal was found to be palatable at replacement levels of $25-100 \%$. From a nutritional standpoint, the best insect candidates are members of the Orthoptera family, which includes grasshoppers, crickets and locusts (Barroso et al., 2014), with silkworm pupae also performing well against fish and soy meals with regard to amino acid content and overall nutritional value (Makkar et al., 2014). Fish are a monogastric species that require a high quality and quantity of protein in their diet, high digestibility of foodstuffs and good palatability (Sánchez-Muros et al., 2014). Although scant, current research demonstrates that insect meal is an ideal alternative or supplement to fish and soy meal for teleosts (Makkar et al., 2014), with the added benefit of being 
more environmentally responsible. When compared to conventional livestock feed production, insects have higher feed conversion efficiency, require less feed to produce $1 \mathrm{~kg}$ of biomass, have higher fecundity, can be raised on organic waste, require less space, and require significantly less water resources (Rumpold and Schlüter, 2013; Sánchez-Muros et al., 2014).

Studies show few, if any, negative effects of using insect meal as a replacement or supplement to traditional fish meal. One area of concern regards the lipid content of terrestrial insects, which is largely comprised of n-6 fatty acids in contrast to fish meal which contains higher concentrations of n-3 fatty acids (Barroso et al., 2014; Sánchez-Muros et al., 2014). However, the poor quality of insect lipids can be modified during the lifecycle of the insects by altering the lipid content of their feed (Sánchez-Muros et al., 2014). One unique aspect that has received little attention is the fact that aquatic insects have a much higher ratio of n-3 fatty acids than do terrestrial insects. This difference is due to the higher proportion of EPA, eicosapentaenoic acid, found in freshwater algae, the main component of aquatic insect diets. EPA is one of several omega-3 fatty acids found in cold-water fatty fish. Aquatic insects may be a superior supplement to traditional fish meal than terrestrial insects due to their high n-3 ratio, and will prove an interesting avenue for future research. Additionally, the lipid content of 
wild versus captive-bred insects was also found to differ in regard to fatty acid content, with wild insects having a lower lipid concentration overall. Typically, amino acid content is more determined by insect taxon, whereas fatty acid profiles of insects most likely reflect the lipid components of their food (Barroso et al., 2014). This is further evidence demonstrating that the lipid content of insects can be modified through changes to their diet.

Amino acid content of insect meal is adequate and similar to that of fish meal, but has been shown to be deficient in methionine, lysine, tryptophan, histidine, and threonine (Barroso et al., 2014; Makkar et al., 2014). Fortunately, these amino acids can be easily supplemented to insect meal during production.

With regard to insect meal digestibility, Barroso (2013) and Sanchez-Muros (2014) found a small reduction in growth rate when insect meal comprised greater than $25 \%$ of feed, while Makkar (2014) found no such reduction in studies of rainbow trout fed insect meal. Such a reduction in growth might be due to the chitin present in insect meal. Chitin is the second most widespread polysaccharide found in nature, after cellulose. It is a non-toxic, biodegradable and biocompatible polymer found in arthropod exoskeletons and the cell walls of fungi, insects and yeast (Cuesta et al., 2003). Barroso (2013) considers chitin "digestively unavailable" material in the diet of teleosts, and it may be inferred that diminished 
growth rates observed when fish are fed insect diets are due to a failure to digest and absorb this material completely (Lindsay et al., 1984). Chitin has poor adhesive properties and may contribute to the friability of pellet feed, aiding in the disintegration of pellets during the flurry of feeding activity, wherein some of the food is rendered unavailable (Lindsay et al., 1984).

Conversely, chitin has also been reported to be an immunostimulant in fishes, though the mechanism remains unclear (Cuesta et al., 2003; Lindsay et al., 1984; Vahedi and Ghodratizadeh, 2011). Immunostimulants have the ability to increase resistance to disease by enhancing nonspecific defense mechanisms (Vahedi and Ghodratizadeh, 2011) and promoting recovery from immunosuppression states caused by stress (Sakai, 1999). Chitin has been shown to increase the activity of the seabream innate immune system (Esteban et al., 2001), and to increase phagocytic activity in fish leukocytes, activating the cellular immune response and enhancing protection against disease (Vahedi and Ghodratizadeh, 2011). Specifically, Sakai (1999) reported that rainbow trout (Oncorhynchus mykiss) injected with chitin in the intraperitoneal region showed stimulated macrophage activities and an increased resistance to Vibrio anguillarum infection. If chitin is both a nondigestible component of insect meal, yet also serves as an immunostimulant, then the mechanism for such an immune system boost 
might be found in the intestinal tract itself: the gut microbiota. Gut microbiota are known to increase immune system function and aid development of the intestinal tract (Bates et al., 2007).

The microbiota of mammalian intestines depends largely on dietary polysaccharides as energy sources (Flint et al., 2008). Fish have also been shown to have resident microbial populations living in their intestinal tracts that utilize undigested materials (Bairagi et al., 2002). This clever evolutionary adaptation of metabolically active microbial societies allows them to salvage energy from nutrients - particularly carbohydrates - that are otherwise nondigestible (Hooper 2002), all while conferring benefits upon the host. These materials serve as prebiotics, which are defined as "...nondigestible food ingredients that are selectively utilized by one or more components of the normal microflora" (Hooper et al., 2002). Prebiotics may play a helpful role in the induction and/or restoration of a disturbed microbiota to its normal beneficial composition (Pérez et al., 2010). Chitin may serve as a prebiotic for fish, possibly stimulating the immune systems of teleosts, thereby making insect meal a perfect addition to hatchery fish food. Lindsay (1984) reported that rainbow trout were not extracting much energy directly from chitin, yet were experiencing the positive immunostimulant effects. Rainbow trout may have endogenous chitinolytic enzymes that could help them 
utilize chitin in addition to the digestion done by gut microbiota. Chitinase genes have been found and sequenced in some marine teleosts, such as Japanese flounder (Paralichthys olivaceus) and striped bass (Morone saxatilis) (Sánchez-Muros et al., 2014). And while chitinolytic and cellulolytic bacteria may not use the solubilized products they generate directly as energy sources, those substrates are then made available to other members of the microbial community through crossfeeding (Flint et al., 2008).

Hatchery stock receive or are inoculated with an intestinal microbiota suited to a domestic environment and processed fish meal feed they are given, whereas wild fish develop a microbiota based on their river environment and food acquisition which is based heavily on an arthropod diet. One possible effect of this is that hatchery stock are then un-prepared to digest wild foodstuffs upon release. These differences in foodstuff consumed may influence the richness and diversity of microbial species found in the intestinal tracts of hatchery and wild fish, which in turn would influence the development of the gut and immune system. Developmental differences based on diet have the potential to affect the health and viability of hatchery fish after they are released. This is the question that stirs curiosity: do hatchery salmonids--steelhead specifically--have different gut microbiota than wild fish from the same river systems? And if so, what effects 
might this have on their physiology and subsequent success in a post-release environment, prior to migration? What effects might a hatchery-derived gut microbiota have on smoltification - the process of preparing the body for life in a pelagic environment? How are the specifics of diet and hatchery environment connected to the types of gut bacteria found in hatchery fish? Despite the continued progression of knowledge about fish immunology and development, the contribution of the normal endogenous microbiota to overall fish health has been so far underestimated (Gómez and Balcázar, 2008). In addition, the effects of an exclusively fish meal diet on the gut microbiota of hatchery fish has not been given due consideration in current literature. We have investigated the gut microbiota diversity of hatchery-reared steelhead from six hatcheries across Oregon and Southern Washington, just prior to release, hoping to shed light onto this scarcely-researched area of aquaculture science.

\subsection{Microbiota Effects on the Host}

The effect of intestinal microbiomes on host physiology is a developing field (Bates et al., 2007). Evidence suggests that differences in intestinal microbiomes are associated with measurable physiological traits such as weight, obesity and metabolism (Cotillard et al., 2013; David et al., 2013; Le Chatelier and et al., 2013) and can be altered by diet and environment (David et al., 2013; Moeller 
et al., 2013). Metagenomic approaches have allowed researchers to measure microbial populations to a highly specific degree by isolating and sequencing conserved areas of DNA such as the 16s ribosomal gene found across bacterial populations (Caporaso et al., 2011; Claesson et al., 2010; Huntley et al., 2012; Salipante et al., 2013). Modern techniques currently allow scientists to identify microbiota to the level of genus and species. In-depth investigation of possible connections between the intestinal microbiome, physiology and development are more economical and more easily accessed than ever before (Lowe, Beth A., et al. 2012).

Vertebrate microbiomes are initiated through external exposures after leaving the germ-free environment of the womb, or in the case of fish, at the earliest exposure to communal water (Roeselers et al., 2011). This reinforces the notion that environment plays a key role in inoculation of an individual with its specific microbiota, regardless of host provenance or domestication status (Cheesman et al., 2011; Roeselers et al., 2011). In other words, organisms living in the same environment may share microbiota, regardless of whether they are of the same lineage or species. Zebrafish of different lineages were found to share common core gut microbiota when put in the same lab environment together (Roeselers et al., 2011). Additionally, gorillas and chimps living sympatrically in a 
shared environment had a more similar core gut microbiota than did chimps of the same species living allopatrically (Moeller et al., 2013).

This has huge implications for hatchery stocks that are expected to thrive in the diametrically opposed environments of hatchery raceways and wild, freshwater river environments where the costly metabolic process of smoltification occurs. How well are hatchery stocks prepared for that metamorphosis? It is known that gut microbiota in fish contribute to important key functions including nutrition, development, immunity and xenobiotic metabolism (Navarrete et al., 2012). Colonization of intestinal mucosal surfaces with normal microbiota has a positive effect on immune regulatory functions of the gut (Pérez et al., 2010) and imbalance may contribute to disease. Host/microbiota interactions are essential to many aspects of normal physiology ranging from metabolic activity to immune homeostasis (Pérez et al., 2010). Karen Guillemin, of the University of Oregon, investigated the link between gut microbiota and epithelial cell development in the digestive tracts of zebrafish and found significant differences between abiotic zebrafish and those with a core gut microbiota. Zebrafish inoculated with a core gut microbiota had increased cell proliferation in intervillus regions of the intestine and a higher percentage of immune cells in the gut than did abiotic fish (Cheesman and Guillemin, 2007). 
Perez (2010) reported that intestinal bacteria were essential for normal development of GALT, or gut-associated lymphatic tissue, and that in the absence of luminal bacteria, B and T cells did not localize in the lamina propria layer of the intestine, and subsequently Immunoglobulin A was not secreted.

The idea that hatchery stock might possess a gut microbiota not as suitable to life in the wild fuels my research. My aim is to illuminate a possible developmental impediment caused by the microbiota of hatchery-reared fish that negatively influences return rates. Current information on the importance of the gut microbiome on health and development explores more subtle but integral processes involving host-microbiome interactions. The increased presence of immune cells in the guts of fish with a developed microbiota serves as evidence for a more involved relationship between the host and its microbiome than was previously thought. An increased presence of immune cells in the guts of fish with healthy microbiota indicates a successful host/microbiota relationship (Bairagi et al., 2002).

My research joins that of other scientists and biologists investigating ways to better prepare hatchery stock for life as juveniles in the wild, freshwater environment they will inhabit post-release, enhancing the possibility of a successful migration to the ocean and a consequent return to freshwater spawning 
grounds. In comparing hatchery steelhead microbiota to that of wild fish, I can add to the knowledge of what role microbiota may be playing in the return rates of wild steelhead, and generate fresh ideas for prebiotic applications in hatchery environments to better prepare hatchery stock for life in the wild. 


\section{Chapter Two}

Gut Microbiota Lipid Metabolism Varies across Rainbow Trout (Oncorhynchus mykiss) Phylogenetic Divide 


\subsection{Introduction}

Vertebrate animals have a diverse microbial community living on and in their bodies, their microbiota. Microbiota play a fundamental role in their hosts' lives and are critical components of normal physiological processes ranging from immune system development to metabolism (Sullam et al., 2015). Microbiota have been studied in numerous vertebrate systems including humans (Goodman et al., 2011; McHardy et al., 2013; Zhou et al., 2016), pigs (Lowe et al. 2012), gorillas and chimpanzees (Moeller et al., 2013), myrmecophagous mammals (Delsuc et al., 2014), pandas (Zhu et al., 2011) and teleosts (Lowrey, Woodhams, Tacchi, \& Salinas, 2015). It is now well documented that the vertebrate gastrointestinal (GI) tract harbors one of the most complex and dynamic microbial ecosystems (Nayak, 2010). Despite this, understanding the effects of these intestinal microbiomes on host physiology is still a developing field (Bates et al., 2007). Evidence suggests that differences in intestinal microbiomes are associated with measurable physiological traits such as weight and obesity (Cotillard et al., 2013) as well as development of the immune system (Montalban-Arques et al., 2015) and defense against environmental pathogens (Lowrey et al., 2015). What would differences in microbiomes potentially indicate? Evidence has shown that a difference of even a single species of bacteria can have profound effects on the host. (Buffington et al., 
2016) explored this question and found that after selective removal, the reintroduction of a single species of bacteria, L. reuteri, restored behavioral alterations similar to autism in humans, highlighting the significant influence of microbiota to host health and function.

Terrestrial vertebrates begin to acquire their commensal gut microbiota at birth from maternal bacteria (Dominguez-Bello et al., 2010) and are colonized by a succession of organisms until a stable community structure is achieved (Cox et al., 2014). This contrasts with teleosts where no direct vertical transmission of maternal bacteria to offspring is evident, but they instead acquire their gut microbiota through communal water exposure prior to first feeding (Ingerslev et al., 2014; Roeselers et al., 2011). Water temperature, habitat type, stress levels, feed type, and feeding conditions can all affect the early colonization of the teleost intestinal microbiome (Nayak, 2010). Each generation of fishes is then dependent on the conditions of their specific rearing environment for the inoculation of their initial gut microbiota (Cheesman and Guillemin, 2007), with environment and diet continuing to impact the evolution of gut microbial communities over time (Sullam et al., 2015).

A wide range of analytical tools is now available to identify the contributions of host, environment, and diet on gut microbiota diversity and 
richness. Gnotobiotic (germ-free) model systems have proven advantageous in identifying characteristics of gut microbiota-host interactions with regard to physical development and immunity, as well as assessment of the manner in which microbiota are acquired from the environment. Studies of gnotobiotic zebrafish have aided researchers in identifying a core gut microbiome, revealing its relationship to development of the GI tract (Llewellyn et al., 2014; Roeselers et al., 2011) and in elucidating specific interactions of microbiota with intestinal mucosal surfaces that affect development of gut-associated lymphatic tissue (GALT) (Pérez et al., 2010). Gnotobiotic mouse models have been used to scrutinize the effect of diet on gut microbiota in monozygotic twins (Ni et al., 2015) and effects of plant and animal-based diets on microbial community structure (Ingerslev et al., 2014). A study of gnotobiotic cod eggs highlights the role of incubator environment in microbial inoculation of the host (Verschuere and Rombaut, 2000). Aquatic environments have been shown to affect gut microbiota composition and are often rich in detritus, including fecal matter from cohabitants. Fecal matter is commonly used in studies of gut microbiota as it is rich in microbial DNA and can be easy to collect without causing harm (Eichmiller et al., 2016). For teleosts, this aquatic exposure to cohabitant fecal matter could play a significant role in determining the composition of microbiota in the intestinal tract. 
Complementing gnotobiotic model systems, high-throughput sequence analyses of $16 \mathrm{~S}$ ribosomal RNA gene sequences are increasingly accessible and affordable to researchers, and have proved to be invaluable in identifying taxonomic diversity down to the species level, illuminating metagenomic variation and distinguishing functional capabilities of commensal gut microbiomes (Claesson et al., 2010; Ghanbari et al., 2015). These advances have led to a surge in research of host-microbiota relationships with regard to diet, environment and host, as well as identifying effects of gut microbial community structure and composition on host health.

The intersection of diet and environment has a significant effect on both composition of gut microbial communities and co-evolution between the gut microbiota and host. In many cases, a direct link between diet and gut microbiota composition can be seen. In Asian seabass (Lates calcarifer) under starvation conditions, gut microbial community structure showed significant differences from a control group (Xia et al., 2014). Diet supplementation with oligosaccharides has been shown to impact gut microbial composition of broiler chickens (Corrigan et al., 2015) as well as supplementation with soybean and insect meal in Atlantic salmon (Salmo salar) (Lock et al., 2015; Nordrum et al., 2000). Diet has also been shown to play an important role in nutrient conversion processes of microbiota 
that make macromolecules available to the host (Montalban-Arques et al., 2015). Diet and environment can also work in tandem to affect gut microbial composition. Distantly related myrmecophagous mammals develop a shared gut microbial profile due to extreme diet specialization caused by environmental restrictions (Delsuc et al., 2014), while gorillas of the same species living allopatrically developed divergent gut microbial communities similar to the gut microbiota of chimpanzees living in the shared environment (Moeller et al., 2013). The direct cause of divergent gut microbiota profiles within a species is not entirely understood. Chimpanzees and gorillas living sympatrically may well share elements of their diet, leading to a similarity in gut microbial profiles. Another possibility is that regular exposure to fecal material from one species can impact the gut microbial composition of another species living nearby. Gnotobiotic mice co-housed with mice having normal endogenous gut microbiota will develop a similar microbial profile via the presence and ingestion of fecal matter in the habitat (Buffington et al., 2016).

Fishes represent great taxonomic and ecological diversity, yet our understanding of the functional significance of their gut microbiota lags behind that of terrestrial vertebrates (Clements et al., 2014). Furthermore, the direct contribution of endogenous microbiota to fish health has been underestimated 
(Gómez and Balcázar, 2008). Recent microbiome research in a variety of teleost species is transforming our understanding of how gut microbiota can affect host development, ecology and evolution (Sullam et al., 2015); however, for important aquaculture species this research has proceeded slowly (Llewellyn et al., 2014). Oncorhynchus mykiss (i.e., rainbow trout that exhibit a freshwater resident life history and steelhead that experience an anadromous life history) are native to waterways of the Western United States (Behnke, 2002). They are a vital species from an aquaculture perspective, as their once-abundant wild populations have been in dramatic decline since the 1950's due to habitat destruction and commercial overexploitation. Many efforts have been taken to restore dwindling populations (Araki et al., 2007; Schmid and Araki, 2010), including the annual release of hundreds of thousands of hatchery-reared fish into the wild (i.e., hatchery stocking) to enhance fish populations for commercial, recreational and conservation interests. Hatchery environments provide researchers valuable in situ locations to test various perturbations of diet and rearing conditions in a controlled setting, and are designed to produce large numbers of big fish (Araki et al., 2007; Brown et al., 2003). However, results of this practice are mixed, as return rates for hatchery fish are half those of wild fish (Chilcote, 2003; Schmid and Araki, 2010). Hatchery systems are nonetheless lauded as success stories by federal 
agencies and related commercial interests. Elucidating reasons for the difference in return rates remains a critical question for members of the aquaculture community as well as conservationists, and research into the gut microbiota of hatchery-reared teleosts is an attractive avenue for exploring the health and subsequent success of fish in the wild across phylogenetic and geographical locations.

Hatchery stocks are often maintained in their geographic region of origin and released at a local level. Released steelhead undergo a process of smoltification (Nichols et al., 2008) during their downstream migration in preparation for life in the marine environment, and eventual return to their natal streams for reproduction. For hatcheries, returning fish are captured as adults and artificially spawned, with the offspring reared in the same local hatchery environment before release and re-initiation of the cycle. In the Pacific Northwest, there are two distinct phylogenetic populations of native rainbow trout/steelhead separated by the Cascade Mountain range (Behnke, 2002; Brown et al., 2004). Across this divide, coastal rainbow trout (O. m. irideus) reside west of the Cascades, and the inland rainbow trout (O. m. gairdneri) on the east (Figure 2). Hatcheries found east of the Cascade Divide raise fish native to eastern waterways, and western hatcheries follow suit. 
In an effort to close the gap between intestinal microbiota physiological

effects on rainbow trout we have analyzed hatchery-raised O. mykiss from across this phylogenetic divide. Specifically, we identified patterns in gut microbiota composition and function in fish sampled from Northern Oregon and Southern Washington. Significant differences in core microbiota taxonomy and functional pathways related to lipid metabolism were found across the known phylogeographic divide of anadromous rainbow trout.

\subsection{Materials and Methods}

\subsubsection{Sample collection and dissection of intestine}

Research fish were collected from six hatcheries across Northern Oregon and Southern Washington (Irrigon, Oak Springs, Round Butte, Skamania, Cowlitz and Cedar Creek) located both east and west of the Cascade Mountain Divide, in order to represent two distinct clades of steelhead found in the Pacific Northwest (Behnke, 2002; Brown et al., 2004). Hatcheries on both sides of the Cascades rear O. mykiss in concrete raceways fed with circulating fresh water from local sources nearby the hatchery. Hatchery raceways are a consistent size and contain similar densities of fish regulated by the Department of Fish and Wildlife. Irrigon (east) and Cowlitz (west) hatcheries utilize well water; Cowlitz uses an ozone purification process for well water during the months of May through November 
to reduce pathogens associated with higher water temperatures. Skamania and Cedar Creek (west) both use river water from the same systems into which their hatchery fish are released. Oak Springs and Round Butte hatcheries (east) have unique water sources; Oak Springs is fed with local spring water and Round Butte is supplied via seepage tunnels in the rock canyon wall abutting the hatchery that contains an upstream reservoir. Water samples were gathered from each hatchery, but did not constitute a high enough water volume to successfully capture microbial content. Monthly health checks are performed at all six hatcheries and if raceways exhibit disease characteristics, oral antibiotics or vaccines are used when necessary. All sample fish were collected from healthy stock.

Diet across all six hatchery locations is highly consistent. Feed used at Skamania (west) and Round Butte (east) hatcheries had a slightly higher lipid content than the feed used at the remaining hatcheries. Ewos Transfer feed used at Skamania and Round Butte contains $48 \%$ protein, $24 \%$ lipids, $1.5 \%$ fiber and $1.3 \%$ phosphorus. BioClark's fry brand of feed used at the remaining four hatcheries contains $47 \%$ protein, $18 \%$ lipids, $1.5 \%$ fiber and $1.3 \%$ phosphorus. Each brand of feed was administered to fish at hatcheries east and west of the Cascade Mountains, likely mitigating any direct effect lipid content in feed may have on 
gut microbiota identified in these two distinct regions. Hatchery information is listed in Table 1.

Ten fish were harvested from each hatchery location and were dispatched with either a sharp blow to the head or with the anesthetic MS-222 (Wilson et al., 2009). The fish were put immediately on ice and transferred to the lab for dissection within 3-6 hours. Upon arrival at the lab, remaining sample fish were kept on ice while the intestinal tract was removed from one sample at a time and its contents collected. All instruments were autoclaved prior to use and were cleaned of debris, rinsed and then soaked in ethanol for 2 minutes in between each dissection. The ventral surface of each fish was wiped with ethanol before incision along the length of the belly from just behind the pectoral fin back to the anal opening. Each intestine was severed near the pyloric sphincter, distal to the stomach and caecae, and approximately 2-3 centimeters proximal to the anal opening. The intestine was removed to a clean surface, and sterile tweezers were used to hold the intestine over a sterile $2 \mathrm{ml}$ tube while the gut contents were gently squeezed from the intestine into the tube.

\subsubsection{DNA Extraction}

Microbial DNA was extracted from the gut contents of each individual sample fish using the Mobio PowerLyzer ${ }^{\mathrm{TM}}$ PowerSoil ${ }^{\circledR}$ DNA isolation Kit (MO 
BIO Laboratories, Carlsbad, CA) using the standard DNA extraction protocol, with an additional pre-processing step; approximately $200 \mathrm{uL}$ of gut contents was added to a clean $2 \mathrm{~mL}$ micro centrifuge tube, followed by $60 \mathrm{uL}$ of cell lysis solution; tubes were gently mixed by shaking, and placed in a water bath of $65^{\circ} \mathrm{C}$ for ten minutes, followed by a heat plate at $95^{\circ} \mathrm{C}$ for ten minutes; after this pre-processing heat treatment, the tube contents were transferred to bead-beating tubes and vortexed at 30 cycles/second for 10 minutes (Wesolowska-Anderson and et al., 2014).

1) After vortexing, bead-beating tubes were centrifuged at $13,000 \mathrm{rpm}$ for 30 seconds at room temperature. 2) $400-500 \mathrm{uL}$ of supernatant was transferred to a clean $2 \mathrm{~mL}$ collection tube and $250 \mathrm{uL}$ of solution 2 was added, which serves to precipitate out non-DNA organic and inorganic matter. Tubes were then vortexed for 30 seconds and incubated at $4^{\circ} \mathrm{C}$ for 5 minutes. 3) Tubes were then centrifuged at 13,000rpm for 1 minute. 4) Avoiding the pellet, up to $600 \mathrm{uL}$ of supernatant was transferred to a clean collection tube. $200 \mathrm{uL}$ of solution 3 was added, to precipitate out remaining non-DNA organic and inorganic materials; tubes were vortexed briefly, and centrifuged at 13,000rpm for 1 minute.

5) Avoiding the pellet, up to $750 \mathrm{uL}$ of supernatant was transferred to a clean collection tube, and 1200uL of solution 4 was added; tubes were again vortexed 
for 5 seconds. Solution 4 is a high concentration salt solution that facilitates DNA binding to the silica filter membrane, allowing contaminants to pass through the filter to be discarded. 6) $675 \mathrm{uL}$ of this supernatant mixture was loaded into a provided spin column and centrifuged at 13,000rpm for 1 minute; this step was repeated until all the supernatant was filtered. 7) 500uL of an ethanol-based wash solution (solution 5) was added and tubes were centrifuged at 13,000rpm for 30 seconds. This step cleans the DNA that is bound to the silica filter membrane of the spin column. 8) After discarding flow through, the tubes were again centrifuged at $13,000 \mathrm{rpm}$ for 1 minute. Spin columns were then carefully placed into clean collection tubes, taking care not to splash any remaining supernatant solution on the spin column filter. 9) 100uL of sterile elution buffer (solution 6) was added directly to the center of each spin column filter. Tubes were incubated for 1 minute to allow full saturation of the silica filter and then centrifuged at 13,000rpm for 1 minute. 10) Spin columns were then discarded and eluted DNA was stored at room temperature for 24 hours prior to quantification. Eluted DNA was quantified on a NanoDrop 2000 Spectrophotometer (Thermo Fisher Scientific, Waltham, MA, USA). Following quantification, samples were stored at $-20^{\circ} \mathrm{C}$ until sequencing.

\subsubsection{PCR validation of $16 S \mathrm{rDNA}$}


Extracted DNA was amplified with polymerase chain reaction (PCR) using standard $503 \mathrm{~F}$ and $806 \mathrm{R}$ primers to validate the presence of the $\mathrm{V} 3 / \mathrm{V} 4$ variable region of the $16 \mathrm{~S}$ ribosomal gene. PCR products were visualized with gel electrophoresis. The expected product length of this region is approximately 300 base pairs, and bands were found of this length using a 1000KB ladder.

\subsubsection{Sequencing and Library Preparation}

Eluted DNA was normalized to 2-10 ng/uL in preparation for sequencing on the Illumina MiSeq platform at the Genome Sequencing and Analysis Facility (GSAF) at the University of Texas at Austin. $25 \mathrm{uL}$ of DNA at 2-10 ng/uL was dispensed into sterile $1.5 \mathrm{~mL}$ micro centrifuge tubes for each of 60 samples, packed with dry ice and sent overnight to GSAF. The V4 hypervariable region of the 16S gene was amplified using the following primers: 515F (GTGYCAGCMGCCGCGGTA) and 806R (TAATCTWTGGGVHCATCAGG), generating a product with a length of 292 base pairs (Table 2). Additional barcode primers were affixed to multiplexed DNA sequences in order to bin them by sample in later analysis steps. PCR was performed in triplicate for each sample and re-pooled for sequencing on the MiSeq platform. Library preparation involved a two-step PCR with dual indexes. The V4 region was targeted to minimize contributions of the teleost host. 


\subsubsection{Initial processing and quality filtering of $16 S$ sequence data}

All sequence data received from GSAF was processed using a microbial community sequence analysis pipeline called QIIME (Quantitative Insights into Microbial Ecology) (Caporaso et al., 2010). QIIME was designed to generate lists of Operational Taxonomic Units (OTUs) from extremely large datasets and to perform both phylogenetic and non-phylogenetic analyses based on the OTUs identified. GSAF generated 250 bp paired-end sequences, which were joined prior to quality filtering. Sequence quality checks were then performed with both custom and default parameters, chimeras were removed, and multiplexed reads were assigned to samples based on their nucleotide barcode. QIIME performs quality filtering based on the characteristics of each sequence, removing any low quality or ambiguous reads. A custom Phred score of 30 was used to filter raw sequence data, indicating that the probability of an incorrect base call is 1 in 1000, or that $99.9 \%$ were correct. QIIME pre-processing of sequence data removed all singleton and doubleton sequences and performed Sequence, UniFrac and OTU based clustering of samples from which the sequences were obtained, using UCLUST and a 97\% similarity threshold. After filtering steps, 2,367,849 total reads were obtained from the 2,411,877 raw reads generated by the GSAF on the Illumina MiSeq platform. The pick_open_reference_otus step in QIIME pipeline 
was used to assign sequences to microbial lineages using the Greengenes reference database for known taxa, and de novo clustering of taxa not found in the reference database. Both open-reference and closed-reference OTU tables were generated for various analyses carried out in this study. Closed-reference OTU tables contain taxa identified in the Greengenes 13_5 or 13_8 databases.

\subsubsection{Statistical analysis of alpha and beta diversity}

A suite of alpha and beta diversity analyses was performed on all samples using the QIIME script core_diversity_analysis.py. Alpha diversity, or withinsample diversity, provides estimates of richness and diversity within the study population. QIIME default metrics were used and include Chao1, which assesses microbial species richness, the Observed Species metric, which counts the number of unique OTUs found within each sample, and the Phylogenetic Diversity (PD Whole-Tree metric, which measures the minimum total length of all the phylogenetic branches required to span a given set of taxa rather than comparing "species" designations. Rarefaction analyses assessed sequence coverage and were sampled at a depth of 1000 sequences, with 48 out of 60 total samples containing a minimum of 1000 sequences per sample. Beta-diversity, or between-sample diversity, was calculated to compare gut microbiomes of all samples originating from different hatcheries, and between east and west locations. Weighted UniFrac 
is a phylogenetically based qualitative metric that accounts for the abundance of observed organisms and is useful for revealing community differences relative to changes in taxon abundance. Unweighted UniFrac, a quantitative metric based on absolute abundance, measures the presence/absence of taxa between samples.

\subsubsection{Identifying a core microbiome}

The compute_core_microbiome.py script in QIIME was used to identify a "core" set of microbiota shared among a chosen percentage of samples within a given metadata category. In this study, to be considered a member of the core microbiota, a taxon must have been present in $80 \%$ of samples from each hatchery and from locations east or west of the Cascade Mountains. Establishing a "core" microbiome is useful for identifying patterns among gut microbial communities across the most samples possible, while capturing as much variation as is possible within the confines of the membership parameters. Alpha and beta diversity analyses for the core microbiota were conducted with the QIIME script core_diversity_analysis.py. Diversity analyses were conducted on the core microbiota constituents, at a depth of only 20 sequences to accommodate extreme variation in number of microbial DNA sequence reads identified across hatchery samples (WSK07 had 12 sequences, while EOS04 had 171,926 sequences). Nonphylogenetic metrics were used and included Bray Curtis, Observed OTUs and 
Chao1, generating a basic picture of core microbiota community structure and diversity. The Bray Curtis dissimilarity index used count data to quantify the compositional differences of bacterial communities between samples from each hatchery site. Input for this analysis included OTU tables representing core gut microbiota constituents identified to the genus level within each individual hatchery environment and within each location category east or west of the Cascades.

\subsubsection{Predicting functional profiles}

PICRUSt (Phylogenetic Investigation of Communities by Reconstruction of Unobserved States) is a software package used to estimate the gene families contributed to a metagenome by bacteria identified through the use of $16 \mathrm{~S}$ rDNA sequencing (Langille et al., 2013). Gene content between closely related organisms is conserved; therefore, by combining the genes present in a common ancestor, along with the information from a fully sequenced genome, a baseline prediction of the gene content of a modern or unstudied organism is possible. From that list of predicted genes, a detailed list of more than 300 specific functional pathways can be identified, generating a picture of metagenomic function for microbiota of interest. For this study 2166 OTUs, or 63\% of all OTUs identified by QIIME that

matched the Greengenes 13_8 reference database, were uploaded into the 
PICRUSt pipeline. 1266 OTUs that clustered de novo were removed from OTU tables before functional analysis. The biom_convert command in QIIME was used to produce files compatible with the PICRUSt program.

The modified files were subsequently uploaded to the Galaxy terminal (https://huttenhower.sph.harvard.edu/galaxy/) for processing and analysis. The first step in the PICRUSt pipeline corrects the input OTU table for known $16 \mathrm{~S}$ rDNA copy numbers for all taxa identified, to better reflect the true organism abundance. Next, a 'virtual' metagenome of KEGG (Kyoto Encyclopedia of Genes and Genomes) ortholog abundances is produced for each sample in the input file. The final step collapses hierarchical data to a specified level, allowing researchers to examine the extent to which genes are involved in multiple pathways and to highlight metagenomic functional roles played by different populations of microbial organisms in a given environment (Kanehisa et al., 2016). Output files from PICRUSt were then visualized using STAMP (Statistical Analysis of Metagenomic Profiles), a graphical interface allowing easy exploration of statistical results highlighting the biological relevance of features in a metagenomic profile (Parks et al., 2014). Two different input files are required as input for the STAMP software program. The first is a profile file containing DNA 
sequence count data and the second is a group metadata file pertaining to categories desired for visualization.

\subsection{Results}

\subsubsection{Microbial diversity analysis}

Gut microbial DNA was isolated through collection of gut contents from 60 total sample fish collected in the spring of 2015 , just prior to release from hatcheries into native streams for eventual migration. A total of $2,411,877$ reads were obtained as raw sequence data from the Genome Sequencing and Analysis Facility (GSAF) at the University of Texas, at Austin. 2, 367, 849 reads remained after paired ends were joined and quality filtering was performed (Table 3). A total of 3432 OTUs were assigned at a 97\% identity threshold, with 2166 (63\%) mapping to the Greengenes 13_8 database and $1266(37 \%)$ clustered de novo as New reference or New Clean Reference OTUs by the QIIME open-reference OTU picking method (See supplemental file S1 for a complete list of 3432 OTUs identified). Rarefaction analysis was conducted to a depth of 1000 reads, with 48 out of 60 total samples containing $>1000$ sequences per sample. Results indicate that rarefaction curves neared saturation (Figure 3). Cedar Creek Hatchery (west) fish were fasted prior to release and did not yield large quantities of microbial DNA so only two samples from Cedar Creek are included in alpha and beta diversity analyses. Irrigon Hatchery (east) had 6 out of 10 samples containing 
adequate read counts. Alpha and beta diversity analyses were therefore carried out with an $n=48$. (Tables 5 and 6 ).

\subsubsection{Taxonomic identification and diversity analysis of "core" microbiota}

For this study, the "core" microbiota are defined as those identified in a minimum of $80 \%$ of samples. Microbial constituents common to eight out of ten fish per hatchery and $80 \%$ of samples in eastern and western locations provided a clearer representation of overall patterns in microbial community composition across the phylogenetic and geographical divide created by the Cascade Mountain range. Firmicutes was the most abundant phylum across all samples $(48.6 \%$ of total in the west and $67.6 \%$ in the east). Next in abundance in eastern locations was Proteobacteria (13.6\%), Actinobacteria (11.4\%), Cyanobacteria, a likely contaminant from ingested water (5.3\%) and Bacteroidetes (2.2\%). Eastern fish, $O$. m. gairdneri, contained a maximum of 5 phyla, 13 families and 15 genera. In contrast, western fish, O. m. irideus, contained only 3 phyla, 5 families and 5 genera. Phyla included Firmicutes (48.6\%), Bacteroidetes (27.2\%) and Actinobacteria (24.2\%) (Figures 4 and 5). A complete list of core taxa can be found in Table 8. (Complete OTU tables can be seen in Files S8 and S9).

Beta diversity analysis of core microbiota indicates a significant difference between east and west hatcheries, with a p-value of 0.004 (Chao1) and 
0.012(Observed-OTUs) (Table 7). A Principal Component Analysis (PCA) was not directly available in QIIME, but a Principal Coordinates Analysis (PCoA) was carried out using a Euclidean Distance Matrix for the core microbiota. Results show clustering of samples into two distinct groupings based on east or west location. (Figure 6). Historically, some Skamania (west) stock have been reared at Oak Springs hatchery, and beta diversity analysis between individual hatcheries east and west of the Cascade Divide did show that Oak Springs fish (east) follow some of the patterns exhibited by Western Cascade fish. However, overall results of comparison between east and west locations were consistent.

2.3.3 Predicted functional metagenomes of east and west rainbow trout intestinal microbiomes

PICRUSt software was used to identify the functional potential of gut microbiome communities belonging to two distinct phylogenetic populations of hatchery-reared steelhead, east and west of the cascade Mountain range. KEGG orthologs were classified at hierarchical levels that included gene subcategories for metabolic function (level 2) and specific metabolic functional pathways (level 3). 13 out of 24 subcategories of metabolic function were found to be significant between the two groups, and included genes associated with cell growth and death $(\mathrm{p}=0.025)$, membrane transport $(\mathrm{p}=0.035)$ and genetic information processing $(p=0.026)$. (For a full list of significant KEGG level 2 subcategories, see figure 7). 
One of the more significant level 2 categories identified included genes associated with lipid metabolism, having a p-value of 0.00120 . Delving further, analysis of the KEGG level 3 functional pathways revealed eight of nineteen functional pathways in the category of lipid metabolism were significantly enriched in the gut microbiota of western fish. These are: linoleic acid metabolism ( $\mathrm{p}=0.000527)$, sphingolipid metabolism $(\mathrm{p}=0.00173)$, lipid biosynthesis proteins $(\mathrm{p}=0.00829)$, biosynthesis of unsaturated fatty acids ( $\mathrm{p}=0.013$ ), lipopolysaccharide biosynthesis $(\mathrm{p}=0.021)$, lipopolysaccharide biosynthesis proteins $(\mathrm{p}=0.027)$, fatty acid metabolism $(\mathrm{p}=0.033)$ and arachidonic acid metabolism $(\mathrm{p}=0.049)$ (Figure 8).

\subsection{Discussion}

Salmon are one of the most iconic creatures of the Pacific Northwest and have a great economic, recreational, and cultural significance. This monophyletic group includes several closely-related salmonid species including the anadromous life history form of rainbow trout (Oncorhynchus mykiss), commonly known as steelhead (Utter and Allendorf, 1994). Despite their monophyletic grouping, the Cascade Mountain range has been shown to separate many salmon species into distinct subspecies, and native steelhead are no exception (Utter et al., 1980) with distinct subspecies found east and west of the Cascade Divide. O. m. irideus, named for the Greek goddess of rainbows (iris), occupy the coastal drainages west of the 
Cascade Mountains and are the primary source of rainbow trout in worldwide aquaculture. The historical natural distribution of this subspecies extended from the Alaskan Peninsula to the northernmost rivers of Baja Mexico. In the Columbia River basin, O. m. irideus is native inland to the Cascade Range and has been observed since the mid to late- $19^{\text {th }}$ century when artificial propagation began. On the east side of the Cascade Range, the "redband" or inland rainbow trout (O. $\mathrm{m}$. gairdneri) are native residents and have been described since the 1940's as far east as Southern Idaho (Behnke, 2002). The native ranges of these two subspecies can be seen in Figure 2.

The longstanding phylogenetic divide between these two populations of $O$. mykiss provided opportunities for coevolution between the genomes and the microbiomes of individuals. Ample research has been conducted regarding coevolution between animals and their external environments (Palkovacs et al., 2009; Thompson, 1994; Vermeij, 1994), but interactions between an organism and its internal environment (i.e., microbiota) are less clear. It is known that symbiotic bacteria help host organisms acquire nutrients (Sullam et al., 2012). In addition, gut microbiota are able to modulate aspects of host metabolism. For example, gut microbiota have been shown to stimulate fatty acid uptake and lipid droplet formation in the intestinal epithelium and liver increasing bioavailability of lipids 
for teleost species (Semova et al., 2012). Additionally, the term "metagenome" describes the combination of host genes and the genes present in trillions of gut microbes that colonize vertebrates, with the vast majority inhabiting the distal gut. This metagenome provides researchers an excellent opportunity to explore the reciprocal adaptations occurring between interacting species that produce physiological changes which can affect metabolic functions in the host (Ley et al., 2008).

Our analysis of intestinal tract $16 \mathrm{~S}$ rDNA microbial sequence data from hatchery-reared steelhead identified abundant inter-individual taxonomic diversity. Using an $80 \%$ minimum occurrence of bacterial taxa among all samples we initially established a "core" microbiota which revealed significant differences among populations east and west of the Cascade Mountain phylogeographic divide. Steelhead sampled from hatcheries east of the Cascades exhibited dramatically higher core gut microbiota diversity than was found in fish from the west side of the mountains (Figures 4 and 5), despite the similarities in diet and rearing conditions revealed in Methods section 2.2.1. Hatcheries on both sides of the Cascades rear O. mykiss in similar environments and use fish meal feed with nearly identical components. Historically, introgression of brood stock from Oak Springs (east) with brood stock from Skamania (west) has previously occurred. 
Despite this introgression, analysis indicates that Oak Springs hatchery continues to group with the east, suggesting limited levels of genetic transfer.

Looking further at the core microbiota found in $80 \%$ of east and west populations, differences emerged as more specific phylogenetic levels were explored. At the family and genus levels, eastern populations contained more than twice the abundance and variety of core microbial taxa as western fish (Tables 8 and 9). Diversity of microbial constituents is often correlated with improved health in humans (Claesson et al., 2012); therefore, identification of microbial community diversity across subspecies of rainbow trout can provide clues as to how to improve the health and success of hatchery fish post-release. Studies of gut microbiota and their relationship to host health is a valuable avenue of research for both aquaculture and conservation interests.

Yet, taxonomic variation is not the only story being told by the commensal gut microbiota of hatchery-reared steelhead. Further analysis of the data using PICRUSt, a gene prediction software that utilizes KEGG ortholog genes and functional pathway information, identified functional differences between the gut microbiota of eastern and western hatchery populations. PICRUSt compiles KEGG ortholog data into three main hierarchical categories. At the most general level, level one, 5 categories are identified: metabolism, genetic information 
processing, environmental information processing, cellular processes and human diseases. These are further subdivided into level two which contains 24 subcategories, and level three containing 330 individual metabolic pathways. At KEGG level two, one of the sub-categories most significantly different between east and west was lipid metabolism, with a p-value of 0.00120 (Figure 7). Gut microbiomes found on the west side of the Cascades showed significant enrichment of lipid metabolism genes, indicating a possible difference at the organismal level regarding how lipids are used by both the host and the microbiota. Lipids are a vital nutritional component for teleost species involved in migration and subsequent return for spawning in natal environments. Lipid content is also an important contribution to species valuable from an aquaculture perspective. For example, wild Copper River Sockeye salmon are highly prized due to their high lipid content derived from their unique geographical range and long inland migration. The Copper River stretches more than 300 miles, and requires the sockeye to rely on large fat reserves to fuel the arduous journey involved in their return to natal streams to spawn (Estabrook, 2010). These fat stores add market value to the sockeye as a commercial species.

Examining lipid metabolism functions of gut microbiota found east and west of the cascades in more depth, analysis of the KEGG level 3 functional 
pathways indicates 8 of 19 pathways involved in lipid metabolism are more highly enriched in western populations than in eastern populations (see figure 8), with pvalues ranging from 0.000527 for linoleic acid metabolism to 0.049 for arachidonic acid metabolism. Identifying this enrichment of metabolic pathways related to lipid metabolism, our research suggests that western host fish may not require as many lipids from the diet. This reduced competition with their own endogenous gut microbiota for access to those lipids could result in a higher abundance of lipid metabolism genes in the gut microbiota to process lipids unused by the host. Eastern fish, with their longer migration distances, require lipids from the diet for energy storage and may be outcompeting their gut microbiota for access to dietary lipids. Additionally, coevolution over time between these longer-migrating fish and their gut microbiota may have selected for a microbiome less dependent on lipids. The fact that metabolic pathways related to membrane transport of carbohydrates were significantly enriched in eastern fish, but not in the west, supports this conclusion.

We hypothesize that the observed differences in lipid metabolism across this phylogenetic divide results from an increased ability of eastern Cascade ( $O$. m. gairdneri) to absorb and utilize lipids taken in via the diet than western Cascade fish, making lipids less available for the intestinal microbiota. Salmonids returning 
to spawn do not eat once they return to freshwater environments, depending instead on fat stores to fuel their journey. Thus, the ability to absorb lipids is a vital factor involved in the success of longer-migrating populations (Crossin et al., 2004). West of the Cascades, individuals (O. m. irideus) appear not to require as high a lipid content due to their shorter migration distances and may not need large lipid reserves for the return trip to spawn, making dietary lipids more available for utilization by the gut microbiota. Future research is needed to measure differences in lipid content between east and west fish and to further explore how coevolution between host and gut microbiota may affect uptake of dietary components related to hatchery fish health and success post-release. This exploration of interaction between the gut microbiome and the host genome creates a valuable opportunity for aquaculture interests to find fish that have this unique genetic background allowing individuals to retain more lipids from the diet. If it is possible to select fish for this specific genetic and microbial profile, without changing diet requirements or rearing conditions, these fish can serve as source populations with a preferred lipid metabolism pattern that can be selected for artificially. This advance would increase the nutritional profile of commercially reared steelhead and increase the availability of this desired phenotype regardless of hatchery location. 
Our research utilizes information from the microbiome to understand the phenotypic implications occurring in segregated populations of hatchery-reared steelhead, further confirming elements of coevolution between an organism and its internal microbiome. This vital piece of the puzzle aids our understanding of how an individual's microbiome helps them succeed differently in divergent geographic and phylogenetic environments and how mechanisms at work in the gut microbial ecosystem truly affect fish health and success. 
Chapter Three

Conclusions 
Intestinal microbiota impact the health and development of their hosts. In Oregon and Southern Washington, our analysis indicates that the two distinct clades of hatchery-reared Oncorhynchus mykiss (O. m irideus in the west and O.m. gairdneri in the east) exhibit significant variation for gut microbiota composition. The observed differences occur in groups east and west of the Cascade Mountain range, mirroring the phylogenetic divergence between the two populations evidenced in earlier research of both nuclear and mitochondrial genomes. A higher degree of taxonomic diversity and richness was found in the core gut microbiota of hatchery reared fish native to the east side of the mountains.

Determining effects of microbial taxonomic variation on host fish depends on understanding environmental variables that exist between hatchery settings. One significant variable between hatcheries is early exposure to communal water. Future investigation of the bacterial content of hatchery water could clarify when and how host fish are inoculated with their endogenous gut microbiota. Moreover, temporal studies could determine if the core gut microbiota differences identified in this study are stable over time and consistent across phylogeographic environments, irrespective of variable hatchery conditions.

In addition to taxonomic variation, lipid metabolism pathways among the gut microbiome of eastern populations were lower, paralleling an increased need 
for host lipids required for longer migration distances to the ocean compared to Western Cascade fish. Future research measuring lipid content of both eastern and western hatchery populations could support this migration distance and lipid requirement hypothesis. To better understand functional differences between eastern and western hatchery salmonids, a metagenomic investigation of proteins and metabolites found in the gut environment could reveal the activity of microbiota with lipid metabolism pathways enriched or reduced in a given population, not just the presence or absence of these genes in the microbiome itself. Understanding the activity of lipid metabolism genes in gut microbiota inhabitants could allow conservationists and aquaculturists to artificially select for steelhead stock with a genetic and microbial profile more conducive to increased lipid uptake by the host. Such stocks would have increased commercial value due to their higher lipid content.

Further investigation of wild steelhead from the same river systems offers future researchers an invaluable source of information into the connection between gut microbiota and return rates of wild and hatchery fish. Identifying taxonomic and functional characteristics endemic to the gut microbiota of wild fish could vastly improve understanding of why wild fish are more successful than hatchery reared fish in wild environments. 


\begin{tabular}{llll}
\hline Hatchery & Address & Phone & Contact \\
\hline Irrigon Hatchery, OR & $\begin{array}{l}\text { 74135 Riverview Lane } \\
\text { Irrigon, OR 97844 }\end{array}$ & (541) 922-5732 & Marc Garst \\
\hline Oak Springs Hatchery, OR & $\begin{array}{l}\text { 85001 Oak Springs Road } \\
\text { Maupin, OR 97037 }\end{array}$ & $(541)$ 325-5327 & Craig Banner \\
\hline Round Butte Hatchery, OR & $\begin{array}{l}\text { 6825 SW Belmont Lane } \\
\text { Madras, OR 97741 }\end{array}$ & $(541)$ 395-2546 & Craig Banner \\
\hline Cedar Creek Hatchery, OR & $\begin{array}{l}\text { 33465 Hwy 22 } \\
\text { Hebo, OR 97122 }\end{array}$ & $(503)$ 392-3485 & Joe Holbert \\
\hline Cowlitz Hatchery, WA & $\begin{array}{l}\text { 165 Osprey Lane } \\
\text { Toledo, WA 98591 }\end{array}$ & (360) 864-6121 & Clint Fitch \\
\hline Skamania Hatchery, WA & $\begin{array}{l}\text { 391 Steelhead Road } \\
\text { Washougal, WA 98671 }\end{array}$ & (360) 837-3131 & John Aleckson \\
& & & \\
\hline
\end{tabular}

\begin{tabular}{|c|c|c|c|c|c|}
\hline Hatchery & State & $\begin{array}{l}\text { \# stocks of } \\
\text { summer } \\
\text { steelhead }\end{array}$ & $\begin{array}{l}\text { Adults } \\
\text { collected/ } \\
\text { spawned at } \\
\text { the hatchery? }\end{array}$ & $\begin{array}{l}\text { Rivers of origin } \\
\text { for hatchery } \\
\text { broodstock }\end{array}$ & $\begin{array}{l}\text { Hatchery } \\
\text { location (east } \\
\text { or west of } \\
\text { Cascades) }\end{array}$ \\
\hline Irrigon & OR & 2 & No & $\begin{array}{l}\text { Imnaha R. } \\
\text { Wallowa R. }\end{array}$ & East \\
\hline Oak Springs * & OR & 2 & No & $\begin{array}{l}\text { Deschutes River, } \\
\text { and Skamania } \\
\text { Hatchery }\end{array}$ & East \\
\hline Round Butte & OR & 1 & Yes & Deschutes River & East \\
\hline Cedar Creek & OR & 2 & Yes & $\begin{array}{l}\text { Nestucca R. } \\
\text { Siltez R. }\end{array}$ & West \\
\hline Cowlitz & WA & 1 & Yes & $\begin{array}{l}\text { Cowlitz River } \\
\text { sub-basin }\end{array}$ & West \\
\hline Skamania & WA & 1 & Yes & $\begin{array}{l}\text { West Fork } \\
\text { Washougal River }\end{array}$ & West \\
\hline
\end{tabular}

* Includes some Skamania Hatchery stock, from west side of Cascades

Sources :

http://wdfw.wa.gov/hatcheries/hgmp/pdf/lower columbia/cowlitz summer sthd 2014.pdf http://wdfw.wa.gov/hatcheries/hgmp/pdf/lower columbia/ssthd eflewis 2012 final.pdf

Table 1: Hatchery Information 
Primers

Hyb515F_rRNA: 5'-

TCGTCGGCAGCGTCAGATGTGTATAAGAGACAGGTGYCAGCMGCCGCGGTA -3’

Hyb806R_rRNA: 3'-

TAATCTWTGGGVHCATCAGGGACAGAGAATATGTGTAGAGGCTCGGGTGCTCTG -5'

rRNA gene-specific sequences in bold and underlined; remainder are Illumina platform-specific sequences.

These primers amplify a 292 base pair region of the $16 \mathrm{~S}$ gene in E. coli.

Table 2: Primers used, V4 region of 16S rDNA for Illumina MiSeq Platform 


\begin{tabular}{|c|c|c|c|c|c|c|c|}
\hline $\begin{array}{l}\text { east } \\
\text { hatcheries }\end{array}$ & $\begin{array}{l}\text { sample } \\
\text { ID }\end{array}$ & $\begin{array}{l}\text { raw } \\
\text { sequence } \\
\text { count }\end{array}$ & $\begin{array}{l}\text { processed } \\
\text { sequence } \\
\text { count }\end{array}$ & $\begin{array}{l}\text { west } \\
\text { hatcheries }\end{array}$ & $\begin{array}{l}\text { sample } \\
\text { ID }\end{array}$ & $\begin{array}{l}\text { raw } \\
\text { sequence } \\
\text { count }\end{array}$ & $\begin{array}{l}\text { processed } \\
\text { sequence } \\
\text { count }\end{array}$ \\
\hline \multirow[t]{10}{*}{ Irrigon } & EIR01 & 147,054 & 147,014 & Cedar & WCC01 & 129 & 124 \\
\hline & EIR02 & 83,644 & 83,009 & \multirow[t]{9}{*}{ Creek $^{*}$} & WCC02 & 258 & 249 \\
\hline & EIR03 & 16,747 & 16,668 & & WCC03 & 442 & 437 \\
\hline & EIR04 & 428 & 421 & & WCC04 & 1,397 & 1,485 \\
\hline & EIR05 & 91,058 & 90,948 & & WCC05 & 244 & 239 \\
\hline & EIR06 & 11,620 & 11,539 & & WCC06 & 66 & 66 \\
\hline & EIR07 & 525 & 510 & & WCC07 & 621 & 615 \\
\hline & EIR08 & 62,016 & 61,978 & & WCC08 & 395 & 393 \\
\hline & EIR09 & 903 & 870 & & WCC09 & 1,138 & 1,084 \\
\hline & EIR10 & 618 & 604 & & WCC10 & 912 & 861 \\
\hline Oak & EOS01 & 11,632 & 11,498 & \multirow[t]{10}{*}{ Cowlitz } & WCH01 & 38,421 & 37,679 \\
\hline \multirow[t]{9}{*}{ Springs } & EOS02 & 10,418 & 10,318 & & WCH02 & 1,849 & 1,781 \\
\hline & EOS03 & 147,995 & 147,902 & & WCH03 & 9,660 & 9,394 \\
\hline & EOS04 & 177,623 & 177,395 & & WCH04 & 59,161 & 58,209 \\
\hline & EOS05 & 94,929 & 94,851 & & WCH05 & 65,450 & 65,150 \\
\hline & EOS06 & 101,107 & 101,076 & & WCH06 & 117,452 & 117,240 \\
\hline & EOS07 & 80,680 & 80,648 & & WCH07 & 19,501 & 19,472 \\
\hline & EOS08 & 67,673 & 67,646 & & WCH08 & 6,167 & 1,683 \\
\hline & EOS09 & 110,200 & 110,103 & & WCH09 & 2,024 & 2,002 \\
\hline & EOS10 & 49,984 & 49,456 & & WCH10 & 10,653 & 8,626 \\
\hline Round & ERB01 & 4,402 & 4,087 & \multirow[t]{10}{*}{ Skamania } & WSK01 & 11,326 & 10,630 \\
\hline \multirow[t]{9}{*}{ Butte } & ERB02 & 22,705 & 21,346 & & WSK02 & 70,001 & 69,905 \\
\hline & ERB03 & 23,911 & 23,448 & & WSK03 & 9,534 & 9,095 \\
\hline & ERB04 & 7,656 & 7,215 & & WSK04 & 99,370 & 99,222 \\
\hline & ERB05 & 6,323 & 6,145 & & WSK05 & 82,677 & 82,587 \\
\hline & ERB06 & 9,743 & 9,038 & & WSK06 & 5,961 & 5,180 \\
\hline & ERB07 & 6,507 & 6,402 & & WSK07 & 149,476 & 149,396 \\
\hline & ERB08 & 23,757 & 23,053 & & WSK08 & 30,438 & 26,041 \\
\hline & ERB09 & 44,731 & 39,943 & & WSK09 & 109,665 & 99,453 \\
\hline & ERB10 & 3,980 & 3,716 & & WSK10 & 87,160 & 80,804 \\
\hline
\end{tabular}

* (Cedar Creek fish were fasted for 2 days in preparation for release prior to sampling)

Total raw sequence count: 2,411,877

Total processed sequence count: 2,367,849

Table 3: Sequence read counts, raw and processed 


\begin{tabular}{|c|c|c|c|c|c|}
\hline $\begin{array}{l}\text { east } \\
\text { hatcheries }\end{array}$ & sample ID & $\begin{array}{l}\text { number of } \\
\text { taxa present }\end{array}$ & $\begin{array}{l}\text { west } \\
\text { hatcheries }\end{array}$ & sample ID & $\begin{array}{l}\text { number of } \\
\text { taxa present }\end{array}$ \\
\hline \multirow[t]{10}{*}{ Irrigon } & EIR01 & 342 & \multirow[t]{10}{*}{ Cedar Creek } & WCC01 & 20 \\
\hline & EIR02 & 437 & & WCC02 & 31 \\
\hline & EIR03 & 230 & & WCC03 & 55 \\
\hline & EIR04 & 56 & & WCC04 & 70 \\
\hline & EIR05 & 280 & & WCC05 & 39 \\
\hline & EIR06 & 169 & & WCC06 & 22 \\
\hline & EIR07 & 87 & & WCC07 & 55 \\
\hline & EIR08 & 150 & & WCC08 & 43 \\
\hline & EIR09 & 127 & & WCC09 & 70 \\
\hline & EIR10 & 88 & & WCC10 & 68 \\
\hline \multirow[t]{10}{*}{ Oak Springs } & EOS01 & 270 & \multirow[t]{10}{*}{ Cowlitz } & WCH01 & 620 \\
\hline & EOS02 & 200 & & WCH02 & 81 \\
\hline & EOS03 & 202 & & WCH03 & 418 \\
\hline & EOS04 & 258 & & WCH04 & 226 \\
\hline & EOS05 & 167 & & WCH05 & 315 \\
\hline & EOS06 & 89 & & WCH06 & 160 \\
\hline & EOS07 & 126 & & WCH07 & 111 \\
\hline & EOS08 & 102 & & WCH08 & 61 \\
\hline & EOS09 & 250 & & WCH09 & 69 \\
\hline & EOS10 & 140 & & WCH10 & 134 \\
\hline \multirow[t]{10}{*}{ Round Butte } & ERB01 & 223 & \multirow[t]{10}{*}{ Skamania } & WSK01 & 172 \\
\hline & ERB02 & 290 & & WSK02 & 133 \\
\hline & ERB03 & 256 & & WSK03 & 130 \\
\hline & ERB04 & 267 & & WSK04 & 151 \\
\hline & ERB05 & 214 & & WSK05 & 119 \\
\hline & ERB06 & 310 & & WSK06 & 187 \\
\hline & ERB07 & 147 & & WSK07 & 117 \\
\hline & ERB08 & 301 & & WSK08 & 397 \\
\hline & ERB09 & 402 & & WSK09 & 607 \\
\hline & ERB10 & 211 & & WSK10 & 532 \\
\hline
\end{tabular}

(Minimum and maximum in bold)

Number of samples: 60

Min: 20 Max: 620 Median: 155.5 Standard Deviation: 137.896

Table 4: Counts of unique taxa present, per sample 


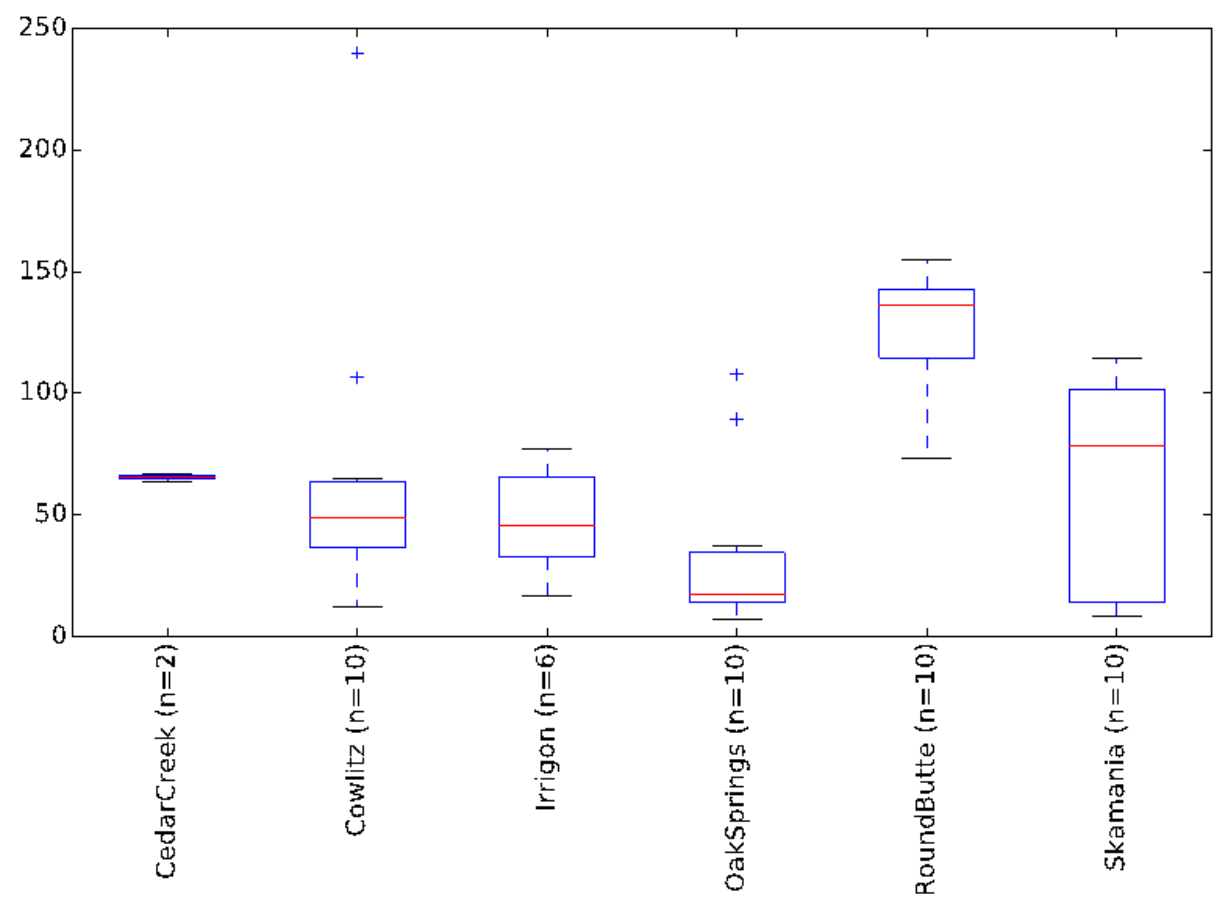

\begin{tabular}{llllllll}
\hline Group1 & Group2 & $\begin{array}{l}\text { Group1 } \\
\text { mean }\end{array}$ & $\begin{array}{l}\text { Group1 } \\
\text { std }\end{array}$ & $\begin{array}{l}\text { Group2 } \\
\text { mean }\end{array}$ & $\begin{array}{l}\text { Group2 } \\
\text { std }\end{array}$ & t stat & p-value \\
\hline Cedar Creek & Round Butte & 65.45 & 1.55 & 126.06 & 24.657 & -3.172 & 0.075 \\
\hline Oak Springs & Round Butte & 34.17 & 33.485 & 126.06 & 24.657 & -6.629 & 0.015 \\
\hline Cowlitz & Oak Springs & 68.04 & 62.437 & 34.17 & 33.485 & 1.434 & 1 \\
\hline Cowlitz & Skamania & 68.04 & 62.437 & 63.26 & 43.130 & 0.188 & 1 \\
\hline Cowlitz & Round Butte & 68.04 & 62.437 & 126.06 & 24.657 & -2.592 & 0.225 \\
\hline Cedar Creek & Oak Springs & 65.45 & 1.55 & 34.17 & 33.485 & 1.205 & 1 \\
\hline Oak Springs & Skamania & 34.17 & 33.485 & 63.26 & 43.130 & -1.598 & 1 \\
\hline Round Butte & Skamania & 126.06 & 24.657 & 63.26 & 43.130 & 3.792 & 0.06 \\
\hline Cowlitz & Cedar Creek & 68.04 & 62.437 & 65.45 & 1.55 & 0.0535 & 1 \\
\hline Oak Springs & Irrigon & 34.17 & 33.485 & 47.7 & 21.277 & -0.830 & 1 \\
\hline Cedar Creek & Skamania & 65.45 & 1.55 & 63.26 & 43.130 & 0.065 & 1 \\
\hline Cowlitz & Irrigon & 68.04 & 62.437 & 47.7 & 21.277 & 0.721 & 1 \\
\hline Cedar Creek & Irrigon & 65.45 & 1.55 & 47.7 & 21.277 & 1.020 & 1 \\
\hline Round Butte & Irrigon & 126.06 & 24.657 & 47.7 & 21.277 & 6.053 & 0.015 \\
\hline Skamania & Irrigon & 63.26 & 43.130 & 47.7 & 21.277 & 0.772 & 1 \\
\hline
\end{tabular}

Table 5: Alpha diversity statistics, all observed OTUs 


\begin{tabular}{lll}
\hline Group 1 & Weighted Unifrac & Unweighted Unifrac \\
\hline Group $\mathbf{2}$ & all within hatchery & all within hatchery \\
\hline $\mathbf{t}$ statistic & all between hatchery & all between hatchery \\
\hline parametric p-value & -9.43430990842 & -7.597010624 \\
\hline $\begin{array}{l}\text { parametric p-value } \\
\text { (Bonferroni-corrected) }\end{array}$ & $2.17436844882 \mathrm{e}-20$ & $6.35 \mathrm{E}-14$ \\
\hline $\begin{array}{l}\text { nonparametric p-value } \\
\text { nonparametric p-value } \\
\text { (Bonferroni-corrected) }\end{array}$ & $5.50115217551 \mathrm{e}-18$ & $1.61 \mathrm{E}-11$ \\
\hline
\end{tabular}

Table 6: Beta diversity statistics, all observed OTUs 


\begin{tabular}{lll}
\hline Location statistics & Chao1 & Observed OTUs \\
\hline Group 1 & west & west \\
\hline Group 2 & east & east \\
\hline Group 1 mean & 3.47857142857 & 3.35 \\
\hline Group 1 std & 1.02106636935 & 0.962326051072 \\
\hline Group 2 mean & 6.380888888889 & 4.8733333333333 \\
\hline Group 2 std & 4.0589578286 & 2.73738723766 \\
\hline t stat & -3.61267177551 & -2.73976055992 \\
\hline p-value & & 0.012 \\
\hline
\end{tabular}

Table 7: Core microbiota non-phylogenetic beta diversity statistics 


\section{Firmicutes}

k_Bacteria; p__Firmicutes; c__Bacilli; o__Lactobacillales; f_; g_; s_

k_Bacteria; p__Firmicutes; c_Bacilli; o__Lactobacillales; f_Enterococcaceae;

g_Enterococcus; s_

k_Bacteria; p_Firmicutes; c__Bacilli; o__Lactobacillales; f__Streptococcaceae;

g__treptococcus; s_

k__Bacteria; P_Firmicutes; c_Clostridia; o__Clostridiales;

f__Peptostreptococcaceae

k__Bacteria; p__Firmicutes; c__Clostridia; o__Clostridiales; f__Clostridiaceae;

g__Clostridium; s_

k_Bacteria; $\quad$ p_Firmicutes; $\quad$ __Clostridia; $\quad$ o_Clostridiales;

f__Peptostreptococcaceae; g__; s_

k_Bacteria; p__Firmicutes; c__Clostridia; o__Clostridiales; f_Clostridiaceae;

g_Clostridium; s_butyricum

k_Bacteria; P_Firmicutes; c__Bacilli; o__Lactobacillales; f_LLactobacillaceae;

g__Lactobacillus; s_

k__Bacteria; p__Firmicutes; c__Bacilli; o__Lactobacillales; f_Streptococcaceae;

g__Streptococcus; s__

k__Bacteria; p__Firmicutes; c__Bacilli; o__Bacillales; f__Staphylococcaceae;

g_Staphylococcus

k__Bacteria; p__Firmicutes; c__Bacilli; o__Lactobacillales; f__Streptococcaceae;

g__Lactococcus; s_

k_Bacteria; p__Firmicutes; c__Bacilli; o__Lactobacillales; f_Lactobacillaceae;

g__Lactobacillus; s_

k__Bacteria; p_Firmicutes; c__Clostridia; o__Clostridiales; f__g_; s_

Proteobacteria

k_Bacteria; p__Proteobacteria; c__Alphaproteobacteria; o_Rickettsiales;

f__mitochondria

Actinobacteria

k_Bacteria; p_Actinobacteria; c_Actinobacteria; o__Actinomycetales;

f__Propionibacteriaceae; g__Propionibacterium; s_acnes

k_Bacteria; p_Actinobacteria; c_Actinobacteria; o_Actinomycetales;

f__Corynebacteriaceae; g__Corynebacterium; s_

Cyanobacteria (likely contaminant)

k__Bacteria; p_Cyanobacteria; c_CChloroplast; o__Streptophyta; f__ g_; s_

Bacteroidetes

k__Bacteria; P_Bacteroidetes; c_Bacteroidia; o_Bacteroidales;

f__Bacteroidaceae; g__Bacteroides; s_ffragilis

Table 8: Table of core microbiota constituents (80\%) East 


\begin{tabular}{|c|c|}
\hline West Hatcheries: Cedar Creek, Cowlitz, Skamania & $\begin{array}{l}\% \text { abundance } \\
\text { phylum level }\end{array}$ \\
\hline$\underline{\text { Firmicutes }}$ & 48.6 \\
\hline $\begin{array}{l}\text { k_Bacteria; p_Firmicutes; c__Clostridia; o__Clostridiales; f_Clostridiaceae; } \\
\text { g__Clostridium; s__ } \\
\text { k__Bacteria; p__Firmicutes; c__Bacilli; o__Bacillales; f__Staphylococcaceae; } \\
\text { g__Staphylococcus }\end{array}$ & \\
\hline $\begin{array}{l}\text { k_Bacteria; } \quad \text { p__Firmicutes; } \quad \text { c__Bacilli; } \quad \text { o__Lactobacillales; } \\
\text { f__Streptococcaceae; g__Lactococcus; s__ }\end{array}$ & \\
\hline $\begin{array}{l}\text { Bacteroidetes } \\
\text { k_Bacteria; } \quad \text { p_Bacteroidetes; } \quad \text { c_Bacteroidia; }\end{array}$ & 27.2 \\
\hline $\begin{array}{l}\text { Actinobacteria } \\
\text { k__acteria; p_Actinobacteria; c_Actinobacteria; o__Actinomycetales; } \\
\text { f__Propionibacteriaceae; g__Propionibacterium; s_acnes }\end{array}$ & 24.2 \\
\hline
\end{tabular}

Table 9: Table of core microbiota constituents (80\%) West 


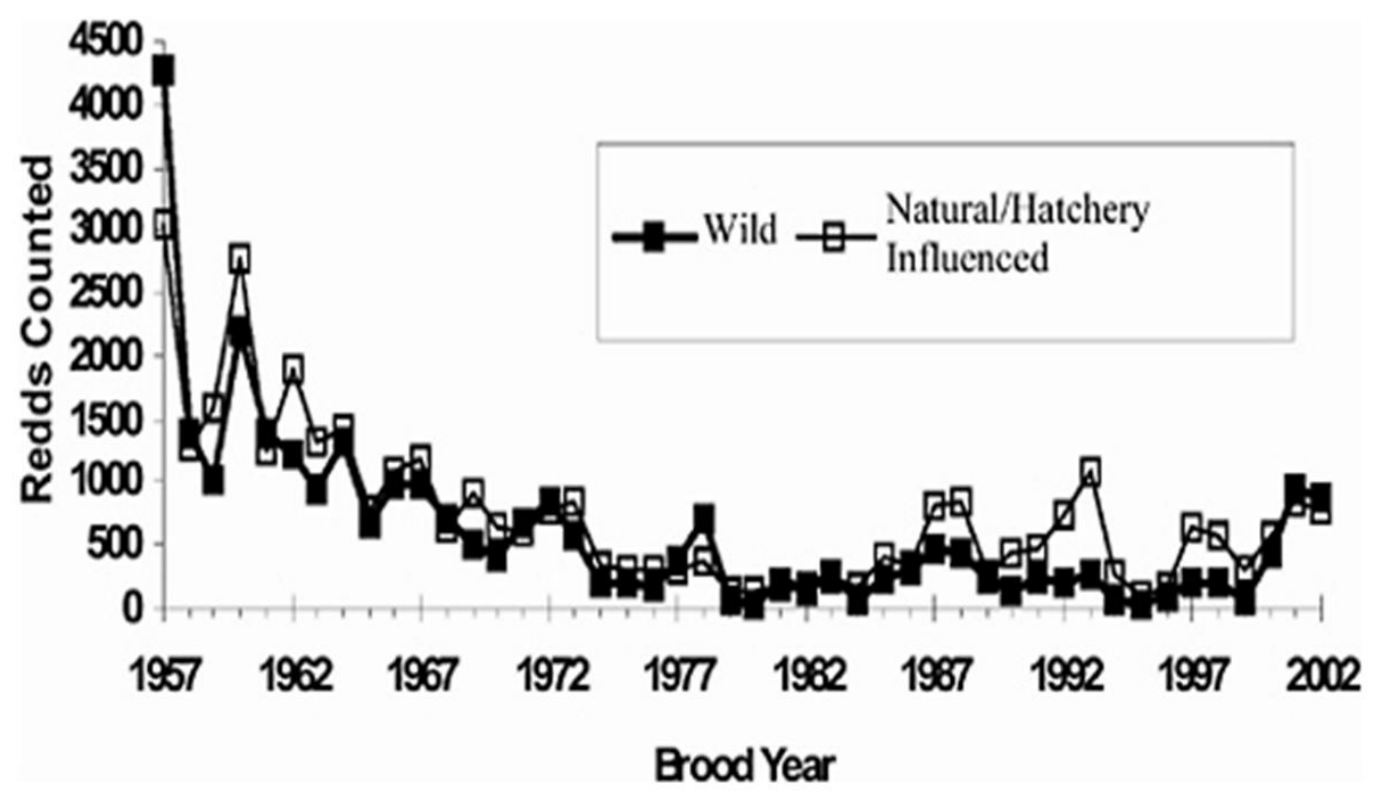

Number of combined spring and summer Chinook redds (thousands) counted in Salmon River drainage, wild and natural/hatchery-influenced trend areas, 19572002.

Source : https://www.nap.edu/read/10962/chapter/6\#80

Figure 1: Redd Counts 


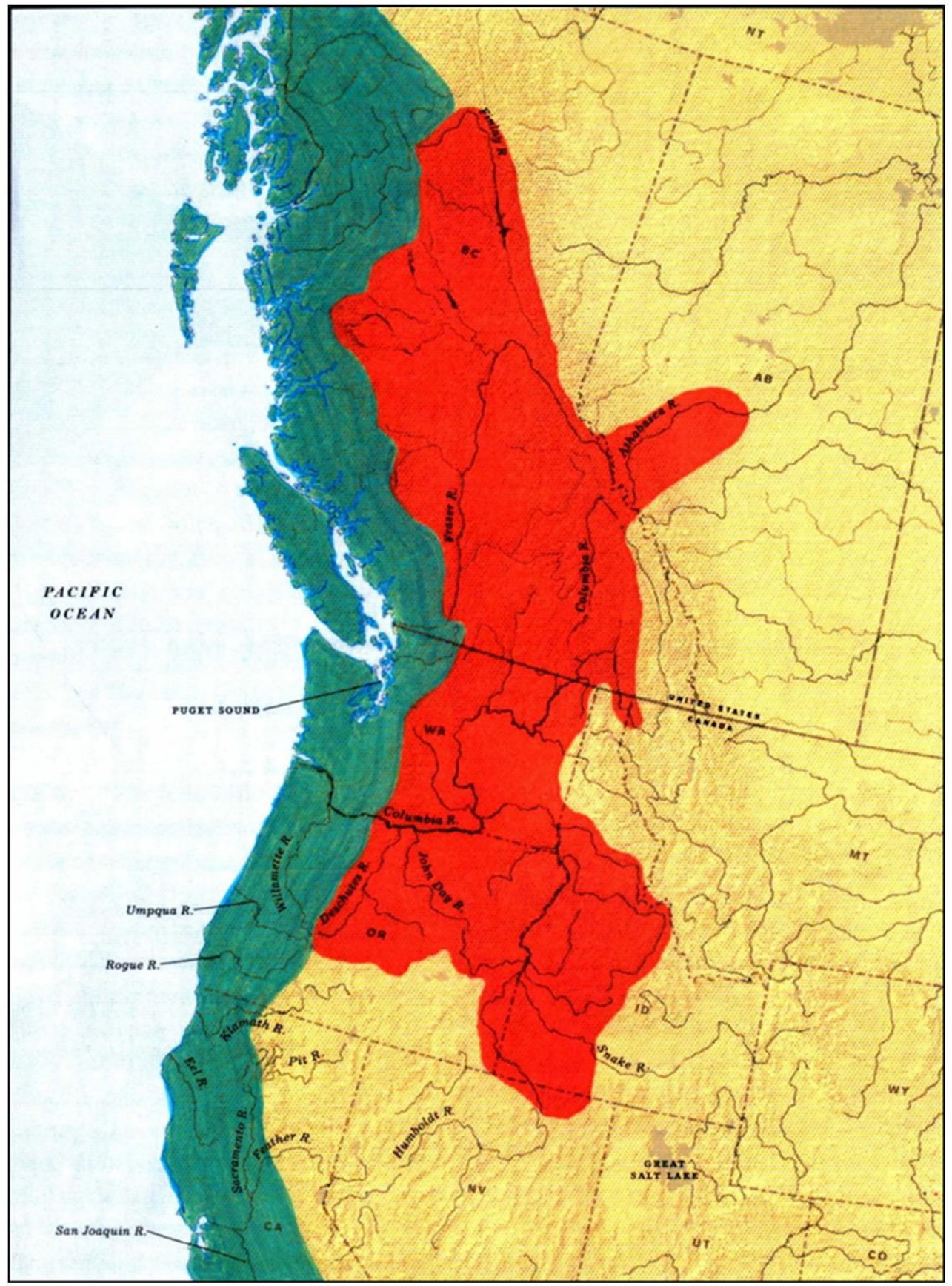

Green: O. m. irideus

Red: O.m. gairdneri

Figure 2: Native range of Oncorhynchus mykiss sub-species in Pacific Northwest (modified from Behnke, 2002, page 84) 

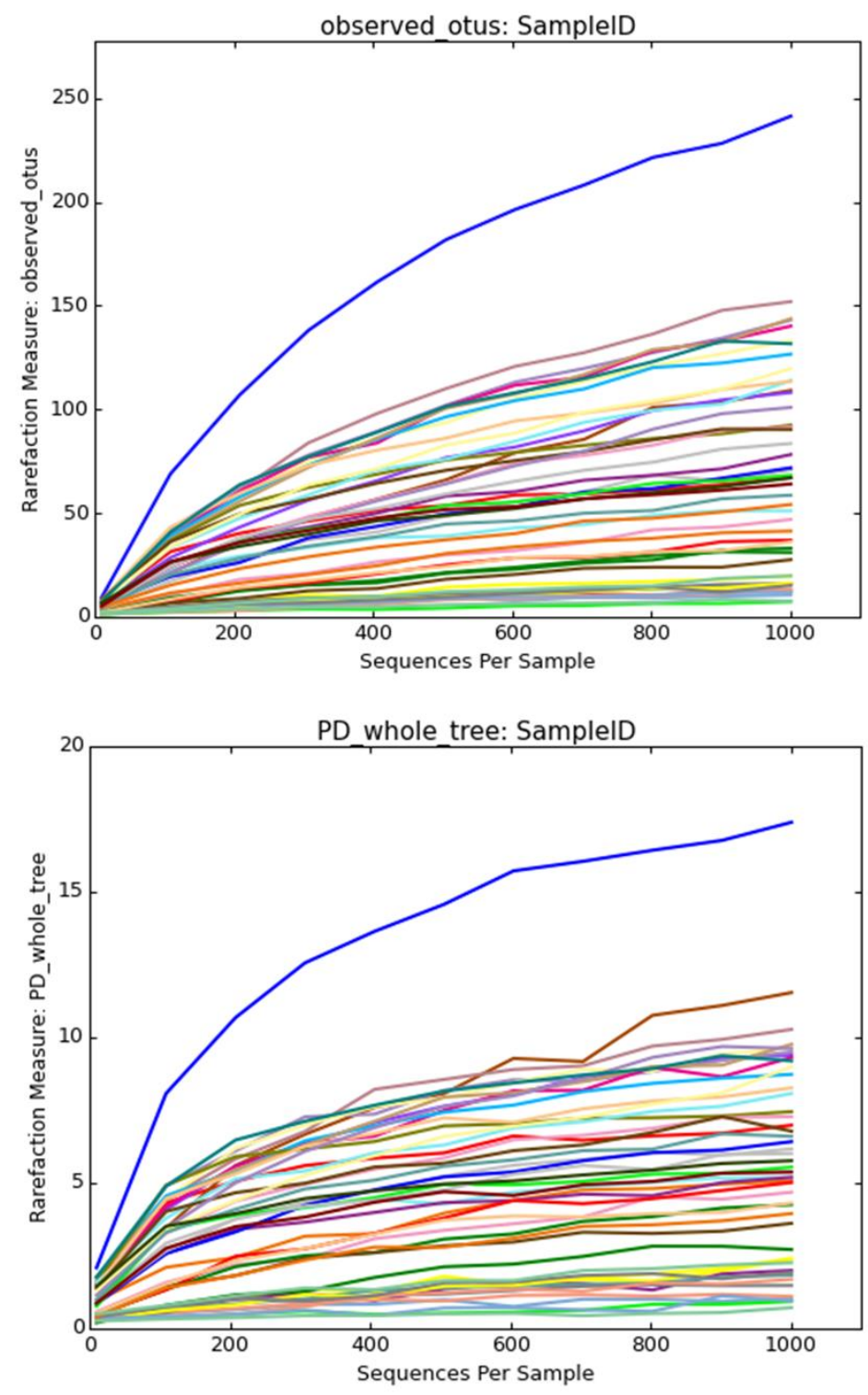

Figures generated at a sampling depth of 1000 Sequences. Each colored line represents a single sample. $\mathrm{n}=48$ out of 60 total samples.

Figure 3: Rarefaction curves, all observed OTUs 


\begin{tabular}{|l|l|}
\hline $\begin{array}{l}\text { West Hatcheries: Cedar Creek, } \\
\text { Cowlitz, Skamania }\end{array}$ & $\begin{array}{l}\text { East Hatcheries: Irrigon, Oak } \\
\text { Springs, Round Butte }\end{array}$ \\
\hline
\end{tabular}
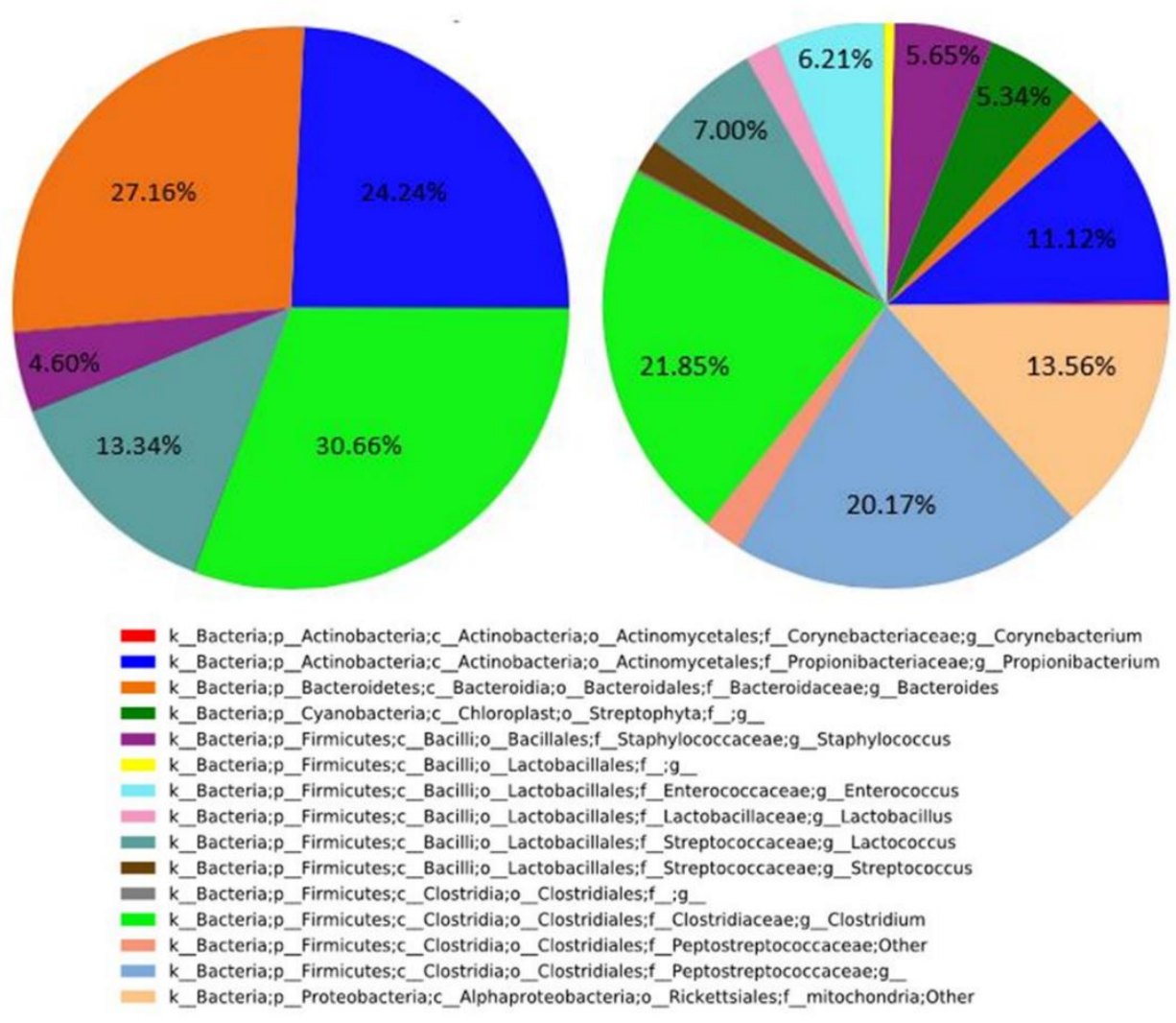

(Unannotated regions $<3.0 \%$ abundance)

Figure 4. Mean relative \% sequence abundance of core microbiota shared between $80 \%$ of hatchery samples, genus level 

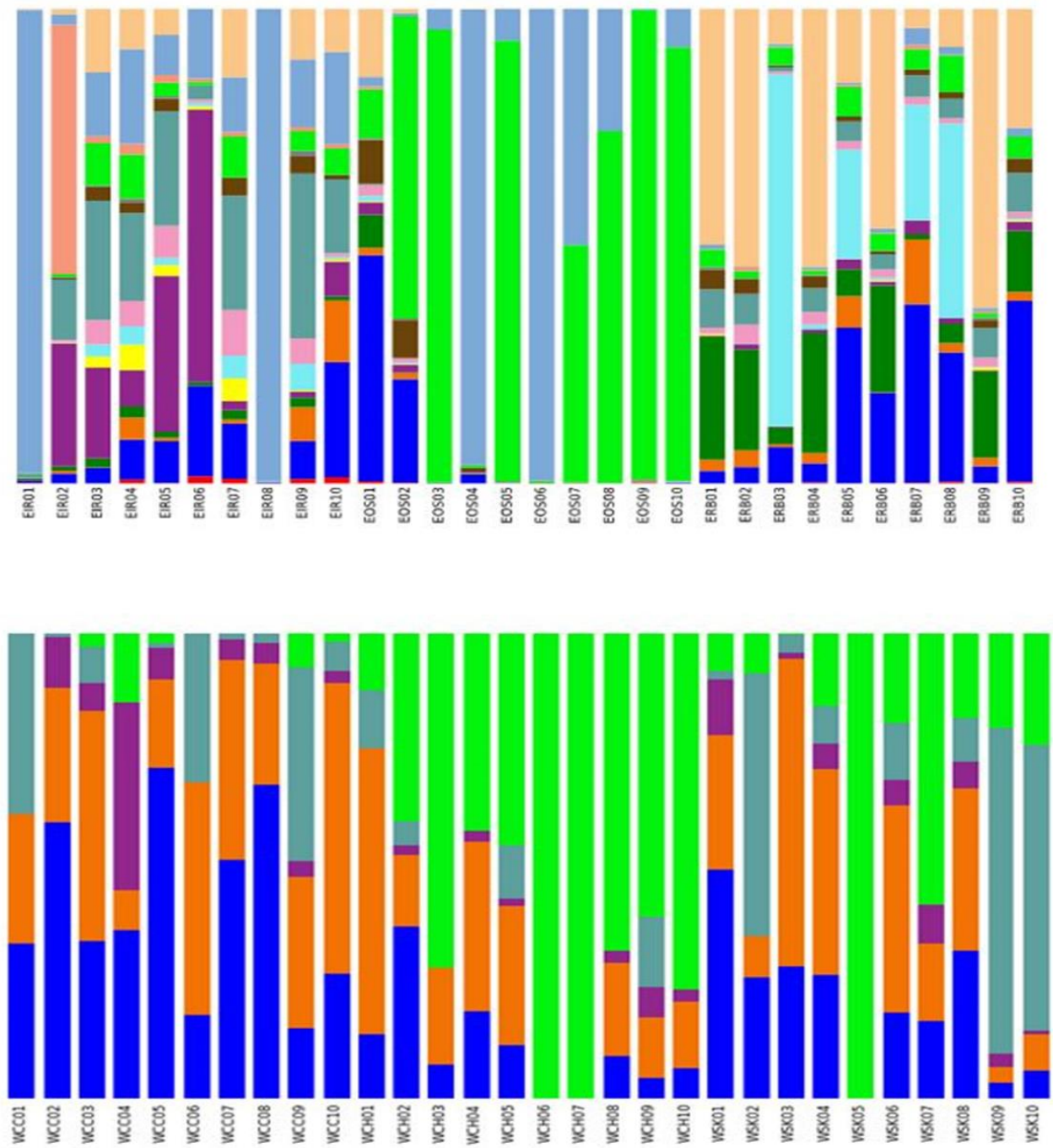

\footnotetext{
- k_Bacteria;p_Actinobacteria;c_Actinobacteria;o_Actinomycetales;f_Corynebacteriaceae; 9 _Corynebacterium

_ Bacteria; _ Actinobacteria;C Actinobacteria;0_Actinomycetales;__Propionibacteriaceae;g_Propionibacterium

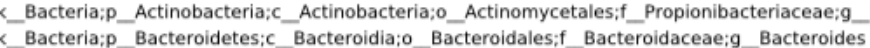

k Bacteria;p Cyanobacteria;c Chloroplast;o Streptophyta; ;

k Bacteria;p Firmicutes;c Bacilli;o Bacillales; Staphylococcaceae;g Staphylococcus k_Bacteria;p_Firmicutes;c_Bacilli;o_Lactobacillales;f_; _

k_Bacteria;P_Firmicutes;c_Bacilli;o_Lactobacillales;f_Enterococcaceae;g_Enterococcus

k Bacteria;p Firmicutes;c Bacilli;0 Lactobacillales; Lactobacillaceae;g Lactobacillus

k_Bacteria;P_Firmicutes;c Bacilli;o_Lactobacillales; Streptococcaceae;g_Lactococcus

n_. kacteria;p_Firmicutes;c_Bacilli;o_Lactobacillales;f_Streptococcaceae;g_Streptococcus

- k_Bacteria;P_Firmicutes;c_Clostridia;o_Clostridiales;f_;g_

- K_Bacteria;p_Firmicutes;c_Clostridia;o_Clostridiales;f_Clostridiaceae;9_Clostridium

K Bacteria;p Firmicutes;c Clostridia;o Clostridiales;f Peptostreptococcaceae;Other

k_Bacteria;p_Firmicutes;c_Clostridia;o_Clostridiales;f_Peptostreptococcaceae;g

k_Bacteria;p_Proteobacteria;c_Alphaproteobacteria;o_Rickettsiales;f_mitochondria;Other
}

Figure 5: Core microbiota ( $80 \%)$ bar charts, per sample (east: top, west: bottom) 

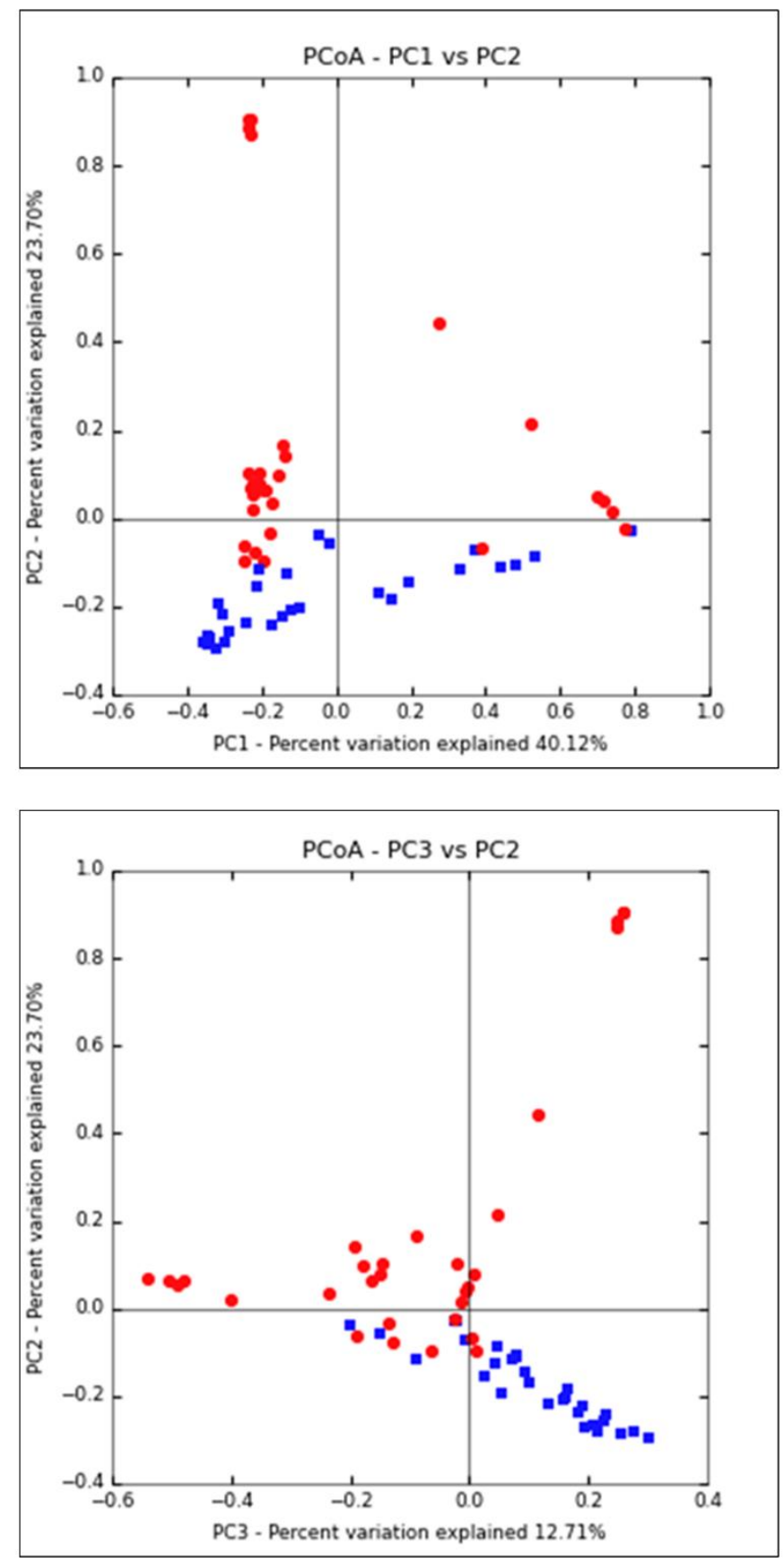

Principal Component Analysis (PCA) done with QIIME using a Principal Coordinates Analysis (PCoA) and a Euclidean distance matrix. Colors signify east and west populations

Figure 6: Principal Component Analysis (PCA) plots, core microbiota 


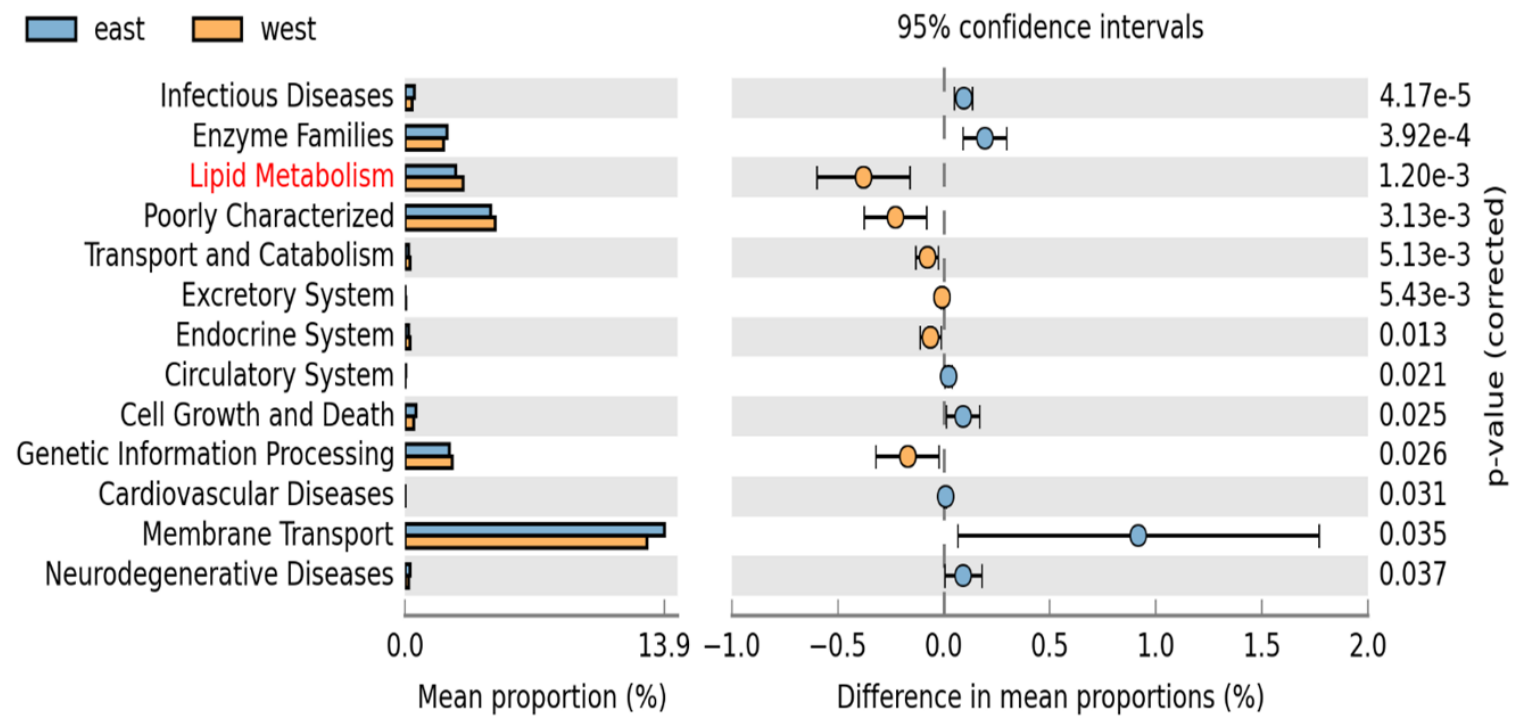

Figure 7: Extended error bar, KEGG level 2 significant sub-categories 


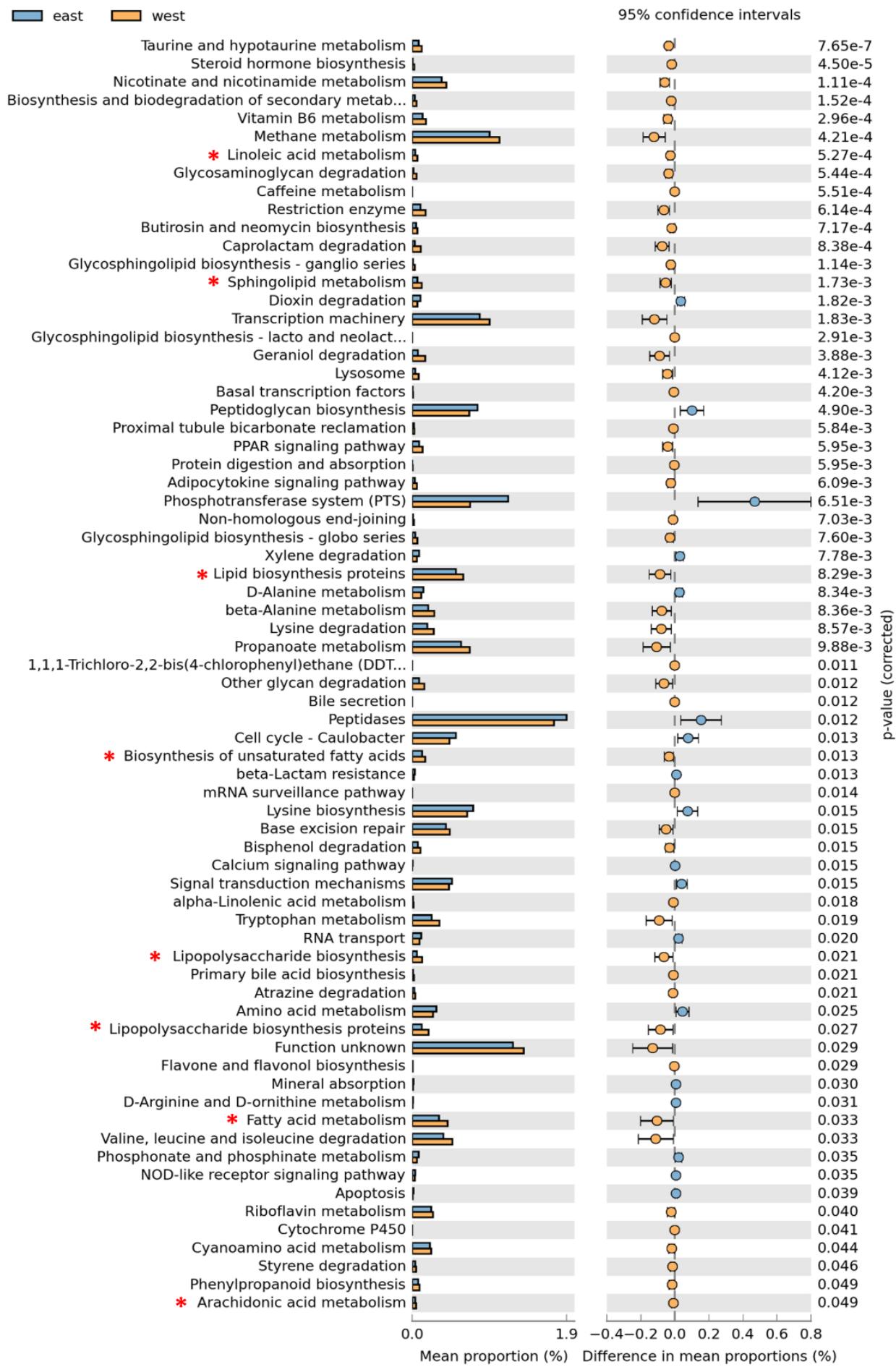

(red asterisks indcate lipid metabolism pathways)

Figure 8: Extended error bar, KEGG level 3 significant functional pathways 


\section{Chapter 1 References}

Araki, H., Ardren, W.R., Olsen, E., Cooper, B., Blouin, M.S., 2007. Reproductive success of captive-bred steelhead trout in the wild: evaluation of three hatchery programs in the Hood river. Conserv. Biol. 21, 181-90. doi:10.1111/j.1523-1739.2006.00564.x

Bairagi, A., Ghosh, K.S., Sen, S.K., Ray, A.K., 2002. Enzyme producing bacterial flora isolated from fish digestive tracts. Aquac. Int. 10, 109-121. doi:10.1023/A:1021355406412

Barroso, F.G., de Haro, C., Sánchez-Muros, M.-J., Venegas, E., Martínez-Sánchez, A., Pérez-Bañón, C., 2014. The potential of various insect species for use as food for fish. Aquaculture 422, 193-201. doi:10.1016/j.aquaculture.2013.12.024

Bates, J.M., Akerlund, J., Mittge, E., Guillemin, K., 2007. Intestinal alkaline phosphatase detoxifies lipopolysaccharide and prevents inflammation in zebrafish in response to the gut microbiota. Cell Host Microbe 2, 371-82. doi:10.1016/j.chom.2007.10.010

Beckman, B.R., Dickhoff, W.W., Zaugg, W.S., 1999. Growth , Smoltification, and Smolt-to-Adult Return of Spring Chinook Salmon from Hatcheries on the Deschutes River, Oregon. Trans. Am. Fish. Soc. 128, 1125-1150. 
Behnke, R.J., 2002. Trout and Salmon of North America, in: Trout and Salmon of North America. Chanticleer Press, Inc., pp. 68-72.

Brown, C., Davidson, T., Laland, K., 2003. Environmental enrichment and prior experience of live prey improve foraging behaviour in hatchery-reared Atlantic salmon. J. Fish Biol. 63, 187-196. doi:10.1046/j.1095-8649.2003.00208.x

Brown, K.H., Patton, S.J., Martin, K.E., Nichols, K.M., Armstrong, R., Thorgaard, G.H., 2004. Reveals Apparent Ancient Hybridization with Westslope Cutthroat Trout. Trans. Am. Fish. Soc. 133, 1078-1088. doi:10.1577/T03-217.1

Buffington, S.A., Di Prisco, G.V., Auchtung, T.A., Ajami, N.J., Petrosino, J.F., Costa-Mattioli, M., 2016. Microbial Reconstitution Reverses Maternal DietInduced Social and Synaptic Deficits in Offspring. Cell 165, 1762-1775. doi:10.1016/j.cell.2016.06.001

Cahill, M.M., 1990. Bacterial flora of fishes: A review. Microb. Ecol. 19, 21-41. doi:10.1007/BF02015051

Caporaso, J.G., Kuczynski, J., Stombaugh, J., Bittinger, K., Bushman, F.D., Costello, E.K., Fierer, N., Peña, A.G., Goodrich, J.K., Gordon, J.I., Huttley, G.A., Kelley, S.T., Knights, D., Koenig, J.E., Ley, R.E., Lozupone, C.A., McDonald, D., Muegge, B.D., Pirrung, M., Reeder, J., Sevinsky, J.R., Turnbaugh, P.J., Walters, 72 
W.A., Widmann, J., Yatsunenko, T., Zaneveld, J., Knight, R., 2010. QIIME allows analysis of high-throughput community sequencing data. Nat. Methods 7, 335-336. doi:10.1038/nmeth.f.303

Caporaso, J.G., Lauber, C.L., Walters, W. a, Berg-Lyons, D., Lozupone, C. a, Turnbaugh, P.J., Fierer, N., Knight, R., 2011. Global patterns of 16S rRNA diversity at a depth of millions of sequences per sample. Proc. Natl. Acad. Sci. U. S. A. 108 Suppl, 4516-4522. doi:10.1073/pnas.1000080107//DCSupplemental.www.pnas.org/cgi/doi/10.1073/pnas.1000080107

Cheesman, S.E., Guillemin, K., 2007. We know you are in there: Conversing with the indigenous gut microbiota. Res. Microbiol. 158, 2-9. doi:10.1016/j.resmic.2006.10.005

Cheesman, S.E., Neal, J.T., Mittge, E., Seredick, B.M., Guillemin, K., 2011. Epithelial cell proliferation in the developing zebrafish intestine is regulated by the Wnt pathway and microbial signaling via Myd88. Proc. Natl. Acad. Sci. U. S. A. 4570-7. doi:10.1073/pnas.1000072107

Chilcote, M.W., 2003. Relationship between natural productivity and the frequency of wild fish in mixed spawning populations of wild and hatchery steelhead ( Oncorhynchus mykiss ). Can. J. Fish Aquat. Sci. 60, 1057-1067. 
doi:10.1139/F03-092

Claesson, M.J., Jeffery, I.B., Conde, S., Power, S.E., O'Connor, E.M., Cusack, S., Harris, H.M., Coakley, M., Lakshminarayanan, B., O'Sullivan, O., Fitzgerald, G.F., Deane, J., O'Connor, M., Harnedy, N., O'Connor, K., O'Mahony, D., van Sinderen, D., Wallace, M., Brennan, L., Stanton, C., Marchesi, J.R., Fitzgerald, A.P., Shanahan, F., Hill, C., Ross, R.P., O’Toole, P.W., 2012. Gut microbiota composition correlates with diet and health in the elderly. Nature $488,178-$ 184. doi:10.1038/nature11319

Claesson, M.J., Wang, Q., O'Sullivan, O., Greene-Diniz, R., Cole, J.R., Ross, R.P., O'Toole, P.W., 2010. Comparison of two next-generation sequencing technologies for resolving highly complex microbiota composition using tandem variable $16 S$ rRNA gene regions. Nucleic Acids Res. 38, e200. doi:10.1093/nar/gkq873

Clements, K.D., Angert, E.R., Montgomery, W.L., Choat, J.H., 2014. Intestinal microbiota in fishes: What's known and what's not. Mol. Ecol. doi:10.1111/mec.12699

Corrigan, A., de Leeuw, M., Penaud-Frézet, S., Dimova, D., Murphy, R.A., 2015. Phylogenetic and functional alterations of bacterial community composition 
in the broiler caecum as a result of mannan oligosaccharide supplementation. Appl. Environ. Microbiol. 81, 3460-3470. doi:10.1128/AEM.04194-14

Cotillard, A., Kennedy, S.P., Kong, L.C., Prifti, E., Pons, N., Le Chatelier, E., Almeida, M., Quinquis, B., Levenez, F., Galleron, N., Gougis, S., Rizkalla, S., Batto, J.M., Renault, P., Dore, J., Zucker, J.D., Clement, K., Ehrlich, S.D., 2013. Dietary intervention impact on gut microbial gene richness. Nature 500, 585588. doi:10.1038/nature12480

Cox, L.M., Yamanishi, S., Sohn, J., Alekseyenko, A. V., Leung, J.M., Cho, I., Kim, S.G., Li, H., Gao, Z., Mahana, D., Zárate Rodriguez, J.G., Rogers, A.B., Robine, N., Loke, P., Blaser, M.J., 2014. Altering the intestinal microbiota during a critical developmental window has lasting metabolic consequences. Cell 158, 705-721. doi:10.1016/j.cell.2014.05.052

Crossin, G.T., Hinch, S.G., Farrell, A.P., Higgs, D.A., Lotto, A.G., Oakes, J.D., Healey, M.C., 2004. Energetics and morphology of sockeye salmon: effects of upriver migratory distance and elevation. J. Fish Biol. 65, 788-810. doi:10.1111/j.0022-1112.2004.00486.x

Cuesta, A., Esteban, M.Á., Meseguer, J., 2003. In vitro effect of chitin particles on the innate cellular immune system of gilthead seabream (Sparus aurata L.). 
Fish Shellfish Immunol. 15, 1-11. doi:10.1016/S1050-4648(02)00134-1

David, L. a., Maurice, C.F., Carmody, R.N., Gootenberg, D.B., Button, J.E., Wolfe, B.E., Ling, A. V., Devlin, a. S., Varma, Y., Fischbach, M. a., Biddinger, S.B., Dutton, R.J., Turnbaugh, P.J., 2013. Diet rapidly and reproducibly alters the human gut microbiome. Nature. doi:10.1038/nature12820

Delsuc, F., Metcalf, J.L., Wegener Parfrey, L., Song, S.J., Gonz??lez, A., Knight, R., 2014. Convergence of gut microbiomes in myrmecophagous mammals. Mol. Ecol. 23, 1301-1317. doi:10.1111/mec.12501

Dominguez-Bello, M.G., Costello, E.K., Contreras, M., Magris, M., Hidalgo, G., Fierer, N., Knight, R., 2010. Delivery mode shapes the acquisition and structure of the initial microbiota across multiple body habitats in newborns. Proc. Natl. Acad. Sci. U. S. A. 107, 11971-11975. doi:10.1073/pnas.1002601107

Eichmiller, J.J., Hamilton, M.J., Staley, C., Sadowsky, M.J., Sorensen, P.W., 2016. Environment shapes the fecal microbiome of invasive carp species. Microbiome 1-13. doi:10.1186/s40168-016-0190-1

Estabrook, B., 2010. How Copper River Salmon Got So Famous - The Atlantic. URL https:/www.theatlantic.com/health/archive/2010/08/how-copper-riversalmon-got-so-famous/60700/ (accessed 4.27.17). 
Esteban, M.A., Cuesta, A., Ortuño, J., Meseguer, J., 2001. Immunomodulatory effects of dietary intake of chitin on gilthead seabream (Sparus aurata L.) innate immune system. Fish Shellfish Immunol. 11, 303-315. doi:10.1006/fsim.2000.0315

Flint, H.J., Bayer, E.A., Rincon, M.T., Lamed, R., White, B.A., 2008. Polysaccharide utilization by gut bacteria: potential for new insights from genomic analysis. Nat. Rev. Microbiol. 6, 121-131. doi:10.1038/nrmicro1817

Ghanbari, M., Kneifel, W., Domig, K.J., 2015. A new view of the fish gut microbiome: Advances from next-generation sequencing. Aquaculture. doi:10.1016/j.aquaculture.2015.06.033

Gómez, G.D., Balcázar, J.L., 2008. A review on the interactions between gut microbiota and innate immunity of fish. FEMS Immunol. Med. Microbiol. 52, 145-154. doi:10.1111/j.1574-695X.2007.00343.x

Goodman, A.L., Kallstrom, G., Faith, J.J., Reyes, A., Moore, A., Dantas, G., Gordon, J.I., 2011. Extensive personal human gut microbiota culture collections characterized and manipulated in gnotobiotic mice. PNAS 108, 6252-6257. doi:10.1073/pnas.1102938108//DCSupplemental.www.pnas.org/cgi/doi/10.1073/pnas.1102938108 
Greene, C.M., Jensen, D.W., Pess, G.R., Steel, E.A., Beamer, E., 2005. Effects of Environmental Conditions during Stream, Estuary, and Ocean Residency on Chinook Salmon Return Rates in the Skagit River, Washington. Trans. Am. Fish. Soc. 134, 1562-1581. doi:10.1577/T05-037.1

Hooper, L. V, Midtvedt, T., Gordon, J.I., 2002. How host-microbial interactions shape the nutrient environment of the mamallian intestine. Annu. Rev. Nutr. 22, 283-307. doi:10.1146/annurev.nutr.22.011602.092259

Huis, A. Van, Itterbeeck, J. Van, Klunder, H., Mertens, E., 2013. Edible insects: future prospects for food and feed security.

Huntley, J., Smith, G., Bauer, M., Gilbert, J. a, Fraser, L., Berg-Lyons, D., Fierer, N., Walters, W. a, Caporaso, J.G., Lauber, C.L., Betley, J., Knight, R., Gormley, N., Owens, S.M., 2012. Ultra-high-throughput microbial community analysis on the Illumina HiSeq and MiSeq platforms. ISME J. 6, 1621-1624. doi:10.1038/ismej.2012.8

Ingerslev, H.C., von Gersdorff Jorgensen, L., Lenz Strube, M., Larsen, N., Dalsgaard, I., Boye, M., Madsen, L., 2014. The development of the gut microbiota in rainbow trout (Oncorhynchus mykiss) is affected by first feeding and diet type. Aquaculture 424-425, 24-34. 
doi:10.1016/j.aquaculture.2013.12.032

Jackson, J.B., Kirby, M.X., Berger, W.H., Bjorndal, K. a, Botsford, L.W., Bourque, B.J., Bradbury, R.H., Cooke, R., Erlandson, J., Estes, J. a, Hughes, T.P., Kidwell, S., Lange, C.B., Lenihan, H.S., Pandolfi, J.M., Peterson, C.H., Steneck, R.S., Tegner, M.J., Warner, R.R., 2001. Historical overfishing and the recent collapse of coastal ecosystems. Science 293, 629-37. doi:10.1126/science.1059199

Kanehisa, M., Sato, Y., Kawashima, M., Furumichi, M., Tanabe, M., 2016. KEGG as a reference resource for gene and protein annotation. Nucleic Acids Res. 44. doi:10.1093/nar/gkv1070

Langille, M., Zaneveld, J., Caporaso, J.G., McDonald, D., Knights, D., Reyes, J., Clemente, J., Burkepile, D., Vega Thurber, R., Knight, R., Beiko, R., Huttenhower, C., 2013. Predictive functional profiling of microbial communities using 16S rRNA marker gene sequences. Nat. Biotechnol. 31, 814-21. doi:10.1038/nbt.2676

Le Chatelier, E., et al., 2013. Richness of human gut microbiome correlates with metabolic markers. Nature 500, 541-546. doi:10.1038/nature12506

Ley, R.E., Ley, R.E., Hamady, M., Lozupone, C., Turnbaugh, P.J., Ramey, R.R., Bircher, J.S., Schlegel, M.L., Tucker, T.A., Schrenzel, M.D., Knight, R., Gordon, 79 
J.I., 2008. Evolution of Mammals and Their Gut Microbes 1647, 1647-1652. doi:10.1126/science.1155725

Lindsay, G.J.H., Walton, M.J., Adron, J.W., Fletcher, T.C., Cho, C.Y., Cowey, C.B., 1984. The growth of rainbow trout (Salmo gairdneri) given diets containing chitin and its relationship to chitinolytic enzymes and chitin digestibility. Aquaculture. doi:10.1016/0044-8486(84)90297-7

Llewellyn, M.S., Boutin, S., Hoseinifar, S.H., Derome, N., 2014. Teleost microbiomes: The state of the art in their characterization, manipulation and importance in aquaculture and fisheries. Front. Microbiol. doi:10.3389/fmicb.2014.00207

Lock, E.R., Arsiwalla, T., Waagbø, R., 2015. Insect larvae meal as an alternative source of nutrients in the diet of Atlantic salmon ( Salmo salar ) postsmolt. Aquac. Nutr. n/a-n/a. doi:10.1111/anu.12343

Lowe, Beth A., Marsh, Terence L., Isaacs-Cosgrove, Natasha, Kirkwood, Roy N., Kiupel, Matti, Mulks, M.H., 2012. Defining the "core microbiome" of the microbial communities in the tonsils of healthy pigs. BMC Microbiol. 12, 20. doi:10.1186/1471-2180-12-20

Lowrey, L., Woodhams, D.C., Tacchi, L., Salinas, I., 2015. Topographical Mapping 80 
of the Rainbow Trout (Oncorhynchus mykiss) Microbiome Reveals a Diverse Bacterial Community with Antifungal Properties in the Skin. Appl. Environ. Microbiol. 81, 6915-25. doi:10.1128/AEM.01826-15

Makkar, H.P.S., Tran, G., Heuzé, V., Ankers, P., 2014. State-of-the-art on use of insects as animal feed. Anim. Feed Sci. Technol. doi:10.1016/j.anifeedsci.2014.07.008

Mansfield, G.S., Desai, A.R., Nilson, S. a., Van Kessel, A.G., Drew, M.D., Hill, J.E., 2010. Characterization of rainbow trout (Oncorhynchus mykiss) intestinal microbiota and inflammatory marker gene expression in a recirculating $\begin{array}{llll}\text { aquaculture } & \text { system. } & \text { Aquaculture } & \text { 307, }\end{array}$ doi:10.1016/j.aquaculture.2010.07.014

McHardy, I.H., Goudarzi, M., Tong, M., Ruegger, P.M., Schwager, E., Weger, J.R., Graeber, T.G., Sonnenburg, J.L., Horvath, S., Huttenhower, C., McGovern, D.P., Fornace, A.J., Borneman, J., Braun, J., 2013. Integrative analysis of the microbiome and metabolome of the human intestinal mucosal surface reveals exquisite inter-relationships. Microbiome 1, 17. doi:10.1186/2049-2618-1-17

Miller, L.M., Close, T., Kapuscinski, a R., 2004. Lower fitness of hatchery and hybrid rainbow trout compared to naturalized populations in Lake Superior 
tributaries. Mol. Ecol. 13, 3379-88. doi:10.1111/j.1365-294X.2004.02347.x

Moeller, A.H., Peeters, M., Ndjango, J.B., Li, Y., Hahn, B.H., Ochman, H., 2013. Sympatric chimpanzees and gorillas harbor convergent gut microbial communities. Genome Res. 23, 1715-1720. doi:10.1101/gr.154773.113

Montalban-Arques, A., De Schryver, P., Bossier, P., Gorkiewicz, G., Mulero, V., Gatlin, D.M., Galindo-Villegas, J., 2015. Selective manipulation of the gut microbiota improves immune status in vertebrates. Front. Immunol. doi:10.3389/fimmu.2015.00512

National Fish Hatchery System, 2013. . Strateg. Hatch. Work. Plan. Rep.

Navarrete, P., Magne, F., Araneda, C., Fuentes, P., Barros, L., Opazo, R., Espejo, R., Romero, J., 2012. PCR-TTGE Analysis of 16S rRNA from Rainbow Trout (Oncorhynchus mykiss) Gut Microbiota Reveals Host-Specific Communities of Active Bacteria. PLoS One 7, e31335. doi:10.1371/journal.pone.0031335

Nayak, S.K., 2010. Role of gastrointestinal microbiota in fish. Aquac. Res. doi:10.1111/j.1365-2109.2010.02546.x

Ni, Y., Li, J., Panagiotou, G., 2015. A molecular-level landscape of diet-gut microbiome interactions: Toward dietary interventions targeting bacterial 
genes. MBio 6, e01263-15. doi:10.1128/mBio.01263-15

Nichols, K.M., Edo, A.F., Wheeler, P. a, Thorgaard, G.H., 2008. The genetic basis of smoltification-related traits in Oncorhynchus mykiss. Genetics 179, 155975. doi:10.1534/genetics.107.084251

Nordrum, S., Bakke-McKellep, a M., Krogdahl, a, Buddington, R.K., 2000. Effects of soybean meal and salinity on intestinal transport of nutrients in Atlantic salmon (Salmo salar L.) and rainbow trout (Oncorhynchus mykiss). Comp. Biochem. Physiol. B. Biochem. Mol. Biol. 125, 317-35.

Palkovacs, E.P., Marshall, M.C., Lamphere, B.A., Lynch, B.R., Weese, D.J., Fraser, D.F., Reznick, D.N., Pringle, C.M., Kinnison, M.T., 2009. Experimental evaluation of evolution and coevolution as agents of ecosystem change in Trinidadian streams. Philos. Trans. R. Soc. Lond. B. Biol. Sci. 364, 1617-28. doi:10.1098/rstb.2009.0016

Parks, D.H., Tyson, G.W., Hugenholtz, P., Beiko, R.G., 2014. STAMP: statistical analysis of taxonomic and functional profiles 30, 3123-3124. doi:10.1093/bioinformatics/btu494

Pérez, T., Balcázar, J.L., Ruiz-Zarzuela, I., Halaihel, N., Vendrell, D., de Blas, I., Múzquiz, J.L., 2010. Host-microbiota interactions within the fish intestinal 
ecosystem. Mucosal Immunol. 3, 355-360. doi:10.1038/mi.2010.12

Roeselers, G., Mittge, E.K., Stephens, W.Z., Parichy, D.M., Cavanaugh, C.M., Guillemin, K., Rawls, J.F., 2011. Evidence for a core gut microbiota in the zebrafish. ISME J. 5, 1595-608. doi:10.1038/ismej.2011.38

Rumpold, B.A., Schlüter, O.K., 2013. Potential and challenges of insects as an innovative source for food and feed production. Innov. Food Sci. Emerg. Technol. 17, 1-11. doi:10.1016/j.ifset.2012.11.005

Sakai, M., 1999. Current research status of fish immunostimulants. Aquaculture 172, 63-92. doi:10.1016/S0044-8486(98)00436-0

Salipante, S.J., Sengupta, D.J., Rosenthal, C., Costa, G., Spangler, J., Sims, E.H., Jacobs, M. a, Miller, S.I., Hoogestraat, D.R., Cookson, B.T., McCoy, C., Matsen, F. a, Shendure, J., Lee, C.C., Harkins, T.T., Hoffman, N.G., 2013. Rapid 16S rRNA next-generation sequencing of polymicrobial clinical samples for diagnosis of complex bacterial infections. PLoS One 8, e65226. doi:10.1371/journal.pone.0065226

Sánchez-Muros, M.J., Barroso, F.G., Manzano-Agugliaro, F., 2014. Insect meal as renewable source of food for animal feeding: A review. J. Clean. Prod. doi:10.1016/j.jclepro.2013.11.068 
Schmid, C., Araki, H., 2010. Is hatchery stocking a help or harm? Aquaculture 308, S2-S11. doi:10.1016/j.aquaculture.2010.05.036

Semova, I., Carten, J.D., Stombaugh, J., MacKey, L.C., Knight, R., Farber, S.A., Rawls, J.F., 2012. Microbiota regulate intestinal absorption and metabolism of fatty acids in the zebrafish. Cell Host Microbe 12, 277-288. doi:10.1016/j.chom.2012.08.003

Storebakken, T., Baeverfjord, G., Lein, I., Roem, A.J., 2000. Differing nutritional responses to dietary soybean meal in rainbow trout ž Oncorhynchus mykiss / and Atlantic salmon ž Salmo salar / q. Aquaculture 190, 49-63.

Sullam, K.E., Essinger, S.D., Lozupone, C.A., O'Connor, M.P., Rosen, G.L., Knight, R., Kilham, S.S., Russell, J.A., 2012. Environmental and ecological factors that shape the gut bacterial communities of fish: A meta-analysis. Mol. Ecol. 21, 3363-3378. doi:10.1111/j.1365-294X.2012.05552.x

Sullam, K.E., Rubin, B.E., Dalton, C.M., Kilham, S.S., Flecker, A.S., Russell, J.A., 2015. Divergence across diet, time and populations rules out parallel evolution in the gut microbiomes of Trinidadian guppies. ISME J. 9, 15081522. doi:10.1038/ismej.2014.231

Thompson, J.N., 1994. The coevolutionary process. University of Chicago Press. 
Tipping, J., 1998. Return rates of hatchery-produced sea-run cutthroat trout reared in a pond versus a standard or baffled raceway. Progress. fish-culturist 109113. doi:10.1577/1548-8640(1998)060<0109

Urke, H.A., Koksvik, J., Arnekleiv, J. V., Hindar, K., Kroglund, F., Kristensen, T., 2010. Seawater tolerance in Atlantic salmon, Salmo salar L., brown trout, Salmo trutta L., and S. salar $\times$ S. trutta hybrids smolt. Fish Physiol. Biochem. 36, 845-853. doi:10.1007/s10695-009-9359-x

Utter, F., Campton, D., Grant, S., Milner, V., Seeb, J., Wishard, L., 1980. Population structures of indigenous salmonid species of the Pacific Northwest, in: McNeil, W.J., Himsworth, D.C. (Eds.), Salmonid Ecosystems of the North Pacific. Oregon State University Press, Corvallis, OR, pp. 285-304.

Utter, F.M., Allendorf, F.W., 1994. Society for Conservation Biology Phylogenetic Relationships Among Species of Oncorhynchus: A Consensus View. Source Conserv. Biol. 8, 864-867.

Vahedi, G., Ghodratizadeh, S., 2011. Effect of Chitin Supplemented Diet on Innate Immune Response of Rainbow Trout. World J. Fish Mar. Sci. 3, 509-513.

Vermeij, G. 1, 1994. The Evolutionary Interaction among Species: Selection, Escalation and Coevolution. Annu. Rev. Ecol. Syst 25, 219-36. 
Verschuere, L., Rombaut, G., 2000. Probiotic bacteria as biological control agents in aquaculture. ... Mol. Biol. ... 64 . doi:10.1128/MMBR.64.4.655671.2000.Updated

Wesolowska-Anderson, et al., 2014. Choice of bacterial DNA extraction method from fecal material influences community structure as evaluated by metagenomic analysis. Microbiome 2, 19. doi:10.1186/2049-2618-2-19

Wilson, J.M., Bunte, R.M., Carty, A.J., 2009. Evaluation of rapid cooling and tricaine methanesulfonate (MS222) as methods of euthanasia in zebrafish (Danio rerio). J. Am. Assoc. Lab. Anim. Sci. 48, 785-9.

Wong, S., Waldrop, T., Summerfelt, S., Davidson, J., Barrows, F., Kenney, B.B., Welch, T., Wiens, G.D., Snekvi, K., Rawls, J.F., Good, C., 2013. Aquacultured rainbow trout (Oncorhynchus mykiss) possess a large core intestinal microbiota that is resistant to variation in diet and rearing density. Appl. Environ. Microbiol. 79, 4974-4984. doi:10.1128/AEM.00924-13

Xia, J.H., Lin, G., Fu, G.H., Wan, Z.Y., Lee, M., Wang, L., Liu, X.J., Yue, G.H., 2014. The intestinal microbiome of fish under starvation. BMC Genomics 15, 266. doi:10.1186/1471-2164-15-266

Zhou, S., Xu, R., He, F., Zhou, J., Wang, Y., Zhou, J., Wang, M., Zhou, W., 2016. 87 
Diversity of gut microbiota metabolic pathways in 10 pairs of Chinese infant twins. PLoS One 11, e0161627. doi:10.1371/journal.pone.0161627

Zhu, L., Wu, Q., Dai, J., Zhang, S., Wei, F., 2011. Evidence of cellulose metabolism by the giant panda gut microbiome. Proc. Natl. Acad. Sci. U. S. A. 108, 177149. doi:10.1073/pnas.1017956108 


\section{Chapter 2 References}

Araki, H., Ardren, W.R., Olsen, E., Cooper, B., Blouin, M.S., 2007. Reproductive success of captive-bred steelhead trout in the wild: evaluation of three hatchery programs in the Hood river. Conserv. Biol. 21, 181-90. doi:10.1111/j.1523-1739.2006.00564.x

Bairagi, A., Ghosh, K.S., Sen, S.K., Ray, A.K., 2002. Enzyme producing bacterial flora isolated from fish digestive tracts. Aquac. Int. 10, 109-121. doi:10.1023/A:1021355406412

Barroso, F.G., de Haro, C., Sánchez-Muros, M.-J., Venegas, E., Martínez-Sánchez, A., Pérez-Bañón, C., 2014. The potential of various insect species for use as food for fish. Aquaculture 422, 193-201. doi:10.1016/j.aquaculture.2013.12.024

Bates, J.M., Akerlund, J., Mittge, E., Guillemin, K., 2007. Intestinal alkaline phosphatase detoxifies lipopolysaccharide and prevents inflammation in zebrafish in response to the gut microbiota. Cell Host Microbe 2, 371-82. doi:10.1016/j.chom.2007.10.010

Beckman, B.R., Dickhoff, W.W., Zaugg, W.S., 1999. Growth , Smoltification, and Smolt-to-Adult Return of Spring Chinook Salmon from Hatcheries on the Deschutes River, Oregon. Trans. Am. Fish. Soc. 128, 1125-1150. 
Behnke, R.J., 2002. Trout and Salmon of North America, in: Trout and Salmon of North America. Chanticleer Press, Inc., pp. 68-72.

Brown, C., Davidson, T., Laland, K., 2003. Environmental enrichment and prior experience of live prey improve foraging behaviour in hatchery-reared Atlantic salmon. J. Fish Biol. 63, 187-196. doi:10.1046/j.1095-8649.2003.00208.x

Brown, K.H., Patton, S.J., Martin, K.E., Nichols, K.M., Armstrong, R., Thorgaard, G.H., 2004. Reveals Apparent Ancient Hybridization with Westslope Cutthroat Trout. Trans. Am. Fish. Soc. 133, 1078-1088. doi:10.1577/T03-217.1

Buffington, S.A., Di Prisco, G.V., Auchtung, T.A., Ajami, N.J., Petrosino, J.F., Costa-Mattioli, M., 2016. Microbial Reconstitution Reverses Maternal DietInduced Social and Synaptic Deficits in Offspring. Cell 165, 1762-1775. doi:10.1016/j.cell.2016.06.001

Cahill, M.M., 1990. Bacterial flora of fishes: A review. Microb. Ecol. 19, 21-41. doi:10.1007/BF02015051

Caporaso, J.G., Kuczynski, J., Stombaugh, J., Bittinger, K., Bushman, F.D., Costello, E.K., Fierer, N., Peña, A.G., Goodrich, J.K., Gordon, J.I., Huttley, G.A., Kelley, S.T., Knights, D., Koenig, J.E., Ley, R.E., Lozupone, C.A., McDonald, D., Muegge, B.D., Pirrung, M., Reeder, J., Sevinsky, J.R., Turnbaugh, P.J., Walters, 
W.A., Widmann, J., Yatsunenko, T., Zaneveld, J., Knight, R., 2010. QIIME allows analysis of high-throughput community sequencing data. Nat. Methods 7, 335-336. doi:10.1038/nmeth.f.303

Caporaso, J.G., Lauber, C.L., Walters, W. a, Berg-Lyons, D., Lozupone, C. a, Turnbaugh, P.J., Fierer, N., Knight, R., 2011. Global patterns of $16 S$ rRNA diversity at a depth of millions of sequences per sample. Proc. Natl. Acad. Sci. U. S. A. 108 Suppl, 4516-4522. doi:10.1073/pnas.1000080107//DCSupplemental.www.pnas.org/cgi/doi/10.1073/pnas.1000080107

Cheesman, S.E., Guillemin, K., 2007. We know you are in there: Conversing with the indigenous gut microbiota. Res. Microbiol. 158, 2-9. doi:10.1016/j.resmic.2006.10.005

Cheesman, S.E., Neal, J.T., Mittge, E., Seredick, B.M., Guillemin, K., 2011. Epithelial cell proliferation in the developing zebrafish intestine is regulated by the Wnt pathway and microbial signaling via Myd88. Proc. Natl. Acad. Sci. U. S. A. 4570-7. doi:10.1073/pnas.1000072107

Chilcote, M.W., 2003. Relationship between natural productivity and the frequency of wild fish in mixed spawning populations of wild and hatchery steelhead ( Oncorhynchus mykiss ). Can. J. Fish Aquat. Sci. 60, 1057-1067. 
doi:10.1139/F03-092

Claesson, M.J., Jeffery, I.B., Conde, S., Power, S.E., O'Connor, E.M., Cusack, S., Harris, H.M., Coakley, M., Lakshminarayanan, B., O'Sullivan, O., Fitzgerald, G.F., Deane, J., O'Connor, M., Harnedy, N., O'Connor, K., O’Mahony, D., van Sinderen, D., Wallace, M., Brennan, L., Stanton, C., Marchesi, J.R., Fitzgerald, A.P., Shanahan, F., Hill, C., Ross, R.P., O'Toole, P.W., 2012. Gut microbiota composition correlates with diet and health in the elderly. Nature $488,178-$ 184. doi:10.1038/nature11319

Claesson, M.J., Wang, Q., O'Sullivan, O., Greene-Diniz, R., Cole, J.R., Ross, R.P., O'Toole, P.W., 2010. Comparison of two next-generation sequencing technologies for resolving highly complex microbiota composition using tandem variable $16 S$ rRNA gene regions. Nucleic Acids Res. 38, e200. doi:10.1093/nar/gkq873

Clements, K.D., Angert, E.R., Montgomery, W.L., Choat, J.H., 2014. Intestinal microbiota in fishes: What's known and what's not. Mol. Ecol. doi:10.1111/mec.12699

Corrigan, A., de Leeuw, M., Penaud-Frézet, S., Dimova, D., Murphy, R.A., 2015. Phylogenetic and functional alterations of bacterial community composition 
in the broiler caecum as a result of mannan oligosaccharide supplementation. Appl. Environ. Microbiol. 81, 3460-3470. doi:10.1128/AEM.04194-14

Cotillard, A., Kennedy, S.P., Kong, L.C., Prifti, E., Pons, N., Le Chatelier, E., Almeida, M., Quinquis, B., Levenez, F., Galleron, N., Gougis, S., Rizkalla, S., Batto, J.M., Renault, P., Dore, J., Zucker, J.D., Clement, K., Ehrlich, S.D., 2013. Dietary intervention impact on gut microbial gene richness. Nature 500, 585588. doi:10.1038/nature12480

Cox, L.M., Yamanishi, S., Sohn, J., Alekseyenko, A. V., Leung, J.M., Cho, I., Kim, S.G., Li, H., Gao, Z., Mahana, D., Zárate Rodriguez, J.G., Rogers, A.B., Robine, N., Loke, P., Blaser, M.J., 2014. Altering the intestinal microbiota during a critical developmental window has lasting metabolic consequences. Cell 158, 705-721. doi:10.1016/j.cell.2014.05.052

Crossin, G.T., Hinch, S.G., Farrell, A.P., Higgs, D.A., Lotto, A.G., Oakes, J.D., Healey, M.C., 2004. Energetics and morphology of sockeye salmon: effects of upriver migratory distance and elevation. J. Fish Biol. 65, 788-810. doi:10.1111/j.0022-1112.2004.00486.x

Cuesta, A., Esteban, M.Á., Meseguer, J., 2003. In vitro effect of chitin particles on the innate cellular immune system of gilthead seabream (Sparus aurata L.). 
Fish Shellfish Immunol. 15, 1-11. doi:10.1016/S1050-4648(02)00134-1

David, L. a., Maurice, C.F., Carmody, R.N., Gootenberg, D.B., Button, J.E., Wolfe, B.E., Ling, A. V., Devlin, a. S., Varma, Y., Fischbach, M. a., Biddinger, S.B., Dutton, R.J., Turnbaugh, P.J., 2013. Diet rapidly and reproducibly alters the human gut microbiome. Nature. doi:10.1038/nature12820

Delsuc, F., Metcalf, J.L., Wegener Parfrey, L., Song, S.J., Gonz??lez, A., Knight, R., 2014. Convergence of gut microbiomes in myrmecophagous mammals. Mol. Ecol. 23, 1301-1317. doi:10.1111/mec.12501

Dominguez-Bello, M.G., Costello, E.K., Contreras, M., Magris, M., Hidalgo, G., Fierer, N., Knight, R., 2010. Delivery mode shapes the acquisition and structure of the initial microbiota across multiple body habitats in newborns. Proc. Natl. Acad. Sci. U. S. A. 107, 11971-11975. doi:10.1073/pnas.1002601107

Eichmiller, J.J., Hamilton, M.J., Staley, C., Sadowsky, M.J., Sorensen, P.W., 2016. Environment shapes the fecal microbiome of invasive carp species. Microbiome 1-13. doi:10.1186/s40168-016-0190-1

Estabrook, B., 2010. How Copper River Salmon Got So Famous - The Atlantic. URL https://www.theatlantic.com/health/archive/2010/08/how-copper-riversalmon-got-so-famous/60700/ (accessed 4.27.17). 
Esteban, M.A., Cuesta, A., Ortuño, J., Meseguer, J., 2001. Immunomodulatory effects of dietary intake of chitin on gilthead seabream (Sparus aurata L.) innate immune system. Fish Shellfish Immunol. 11, 303-315. doi:10.1006/fsim.2000.0315

Flint, H.J., Bayer, E.A., Rincon, M.T., Lamed, R., White, B.A., 2008. Polysaccharide utilization by gut bacteria: potential for new insights from genomic analysis. Nat. Rev. Microbiol. 6, 121-131. doi:10.1038/nrmicro1817

Ghanbari, M., Kneifel, W., Domig, K.J., 2015. A new view of the fish gut microbiome: Advances from next-generation sequencing. Aquaculture. doi:10.1016/j.aquaculture.2015.06.033

Gómez, G.D., Balcázar, J.L., 2008. A review on the interactions between gut microbiota and innate immunity of fish. FEMS Immunol. Med. Microbiol. 52, 145-154. doi:10.1111/j.1574-695X.2007.00343.x

Goodman, A.L., Kallstrom, G., Faith, J.J., Reyes, A., Moore, A., Dantas, G., Gordon, J.I., 2011. Extensive personal human gut microbiota culture collections characterized and manipulated in gnotobiotic mice. PNAS 108, 6252-6257. doi:10.1073/pnas.1102938108//DCSupplemental.www.pnas.org/cgi/doi/10.1073/pnas.1102938108 
Greene, C.M., Jensen, D.W., Pess, G.R., Steel, E.A., Beamer, E., 2005. Effects of Environmental Conditions during Stream, Estuary, and Ocean Residency on Chinook Salmon Return Rates in the Skagit River, Washington. Trans. Am. Fish. Soc. 134, 1562-1581. doi:10.1577/T05-037.1

Hooper, L. V, Midtvedt, T., Gordon, J.I., 2002. How host-microbial interactions shape the nutrient environment of the mamallian intestine. Annu. Rev. Nutr. 22, 283-307. doi:10.1146/annurev.nutr.22.011602.092259

Huis, A. Van, Itterbeeck, J. Van, Klunder, H., Mertens, E., 2013. Edible insects: future prospects for food and feed security.

Huntley, J., Smith, G., Bauer, M., Gilbert, J. a, Fraser, L., Berg-Lyons, D., Fierer, N., Walters, W. a, Caporaso, J.G., Lauber, C.L., Betley, J., Knight, R., Gormley, N., Owens, S.M., 2012. Ultra-high-throughput microbial community analysis on the Illumina HiSeq and MiSeq platforms. ISME J. 6, 1621-1624. doi:10.1038/ismej.2012.8

Ingerslev, H.C., von Gersdorff Jorgensen, L., Lenz Strube, M., Larsen, N., Dalsgaard, I., Boye, M., Madsen, L., 2014. The development of the gut microbiota in rainbow trout (Oncorhynchus mykiss) is affected by first feeding and diet type. Aquaculture 424-425, 24-34. 
doi:10.1016/j.aquaculture.2013.12.032

Jackson, J.B., Kirby, M.X., Berger, W.H., Bjorndal, K. a, Botsford, L.W., Bourque, B.J., Bradbury, R.H., Cooke, R., Erlandson, J., Estes, J. a, Hughes, T.P., Kidwell, S., Lange, C.B., Lenihan, H.S., Pandolfi, J.M., Peterson, C.H., Steneck, R.S., Tegner, M.J., Warner, R.R., 2001. Historical overfishing and the recent collapse of coastal ecosystems. Science 293, 629-37. doi:10.1126/science.1059199

Kanehisa, M., Sato, Y., Kawashima, M., Furumichi, M., Tanabe, M., 2016. KEGG as a reference resource for gene and protein annotation. Nucleic Acids Res. 44 . doi:10.1093/nar/gkv1070

Langille, M., Zaneveld, J., Caporaso, J.G., McDonald, D., Knights, D., Reyes, J., Clemente, J., Burkepile, D., Vega Thurber, R., Knight, R., Beiko, R., Huttenhower, C., 2013. Predictive functional profiling of microbial communities using 16S rRNA marker gene sequences. Nat. Biotechnol. 31, 814-21. doi:10.1038/nbt.2676

Le Chatelier, E., et al., 2013. Richness of human gut microbiome correlates with metabolic markers. Nature 500, 541-546. doi:10.1038/nature12506

Ley, R.E., Ley, R.E., Hamady, M., Lozupone, C., Turnbaugh, P.J., Ramey, R.R., Bircher, J.S., Schlegel, M.L., Tucker, T.A., Schrenzel, M.D., Knight, R., Gordon, 
J.I., 2008. Evolution of Mammals and Their Gut Microbes 1647, 1647-1652. doi:10.1126/science.1155725

Lindsay, G.J.H., Walton, M.J., Adron, J.W., Fletcher, T.C., Cho, C.Y., Cowey, C.B., 1984. The growth of rainbow trout (Salmo gairdneri) given diets containing chitin and its relationship to chitinolytic enzymes and chitin digestibility. Aquaculture. doi:10.1016/0044-8486(84)90297-7

Llewellyn, M.S., Boutin, S., Hoseinifar, S.H., Derome, N., 2014. Teleost microbiomes: The state of the art in their characterization, manipulation and importance in aquaculture and fisheries. Front. Microbiol. doi:10.3389/fmicb.2014.00207

Lock, E.R., Arsiwalla, T., Waagbø, R., 2015. Insect larvae meal as an alternative source of nutrients in the diet of Atlantic salmon ( Salmo salar ) postsmolt. Aquac. Nutr. n/a-n/a. doi:10.1111/anu.12343

Lowe, Beth A., Marsh, Terence L., Isaacs-Cosgrove, Natasha, Kirkwood, Roy N., Kiupel, Matti, Mulks, M.H., 2012. Defining the "core microbiome" of the microbial communities in the tonsils of healthy pigs. BMC Microbiol. 12, 20. doi:10.1186/1471-2180-12-20

Lowrey, L., Woodhams, D.C., Tacchi, L., Salinas, I., 2015. Topographical Mapping 
of the Rainbow Trout (Oncorhynchus mykiss) Microbiome Reveals a Diverse Bacterial Community with Antifungal Properties in the Skin. Appl. Environ. Microbiol. 81, 6915-25. doi:10.1128/AEM.01826-15

Makkar, H.P.S., Tran, G., Heuzé, V., Ankers, P., 2014. State-of-the-art on use of insects as animal feed. Anim. Feed Sci. Technol. doi:10.1016/j.anifeedsci.2014.07.008

Mansfield, G.S., Desai, A.R., Nilson, S. a., Van Kessel, A.G., Drew, M.D., Hill, J.E., 2010. Characterization of rainbow trout (Oncorhynchus mykiss) intestinal microbiota and inflammatory marker gene expression in a recirculating $\begin{array}{llll}\text { aquaculture } & \text { system. } & \text { Aquaculture } & \text { 307, }\end{array}$ doi:10.1016/j.aquaculture.2010.07.014

McHardy, I.H., Goudarzi, M., Tong, M., Ruegger, P.M., Schwager, E., Weger, J.R., Graeber, T.G., Sonnenburg, J.L., Horvath, S., Huttenhower, C., McGovern, D.P., Fornace, A.J., Borneman, J., Braun, J., 2013. Integrative analysis of the microbiome and metabolome of the human intestinal mucosal surface reveals exquisite inter-relationships. Microbiome 1, 17. doi:10.1186/2049-2618-1-17

Miller, L.M., Close, T., Kapuscinski, a R., 2004. Lower fitness of hatchery and hybrid rainbow trout compared to naturalized populations in Lake Superior 
tributaries. Mol. Ecol. 13, 3379-88. doi:10.1111/j.1365-294X.2004.02347.x

Moeller, A.H., Peeters, M., Ndjango, J.B., Li, Y., Hahn, B.H., Ochman, H., 2013. Sympatric chimpanzees and gorillas harbor convergent gut microbial communities. Genome Res. 23, 1715-1720. doi:10.1101/gr.154773.113

Montalban-Arques, A., De Schryver, P., Bossier, P., Gorkiewicz, G., Mulero, V., Gatlin, D.M., Galindo-Villegas, J., 2015. Selective manipulation of the gut microbiota improves immune status in vertebrates. Front. Immunol. doi:10.3389/fimmu.2015.00512

National Fish Hatchery System, 2013. . Strateg. Hatch. Work. Plan. Rep.

Navarrete, P., Magne, F., Araneda, C., Fuentes, P., Barros, L., Opazo, R., Espejo, R., Romero, J., 2012. PCR-TTGE Analysis of 16S rRNA from Rainbow Trout (Oncorhynchus mykiss) Gut Microbiota Reveals Host-Specific Communities of Active Bacteria. PLoS One 7, e31335. doi:10.1371/journal.pone.0031335

Nayak, S.K., 2010. Role of gastrointestinal microbiota in fish. Aquac. Res. doi:10.1111/j.1365-2109.2010.02546.x

Ni, Y., Li, J., Panagiotou, G., 2015. A molecular-level landscape of diet-gut microbiome interactions: Toward dietary interventions targeting bacterial genes. MBio 6, e01263-15. doi:10.1128/mBio.01263-15 
Nichols, K.M., Edo, A.F., Wheeler, P. a, Thorgaard, G.H., 2008. The genetic basis of smoltification-related traits in Oncorhynchus mykiss. Genetics 179, 155975. doi:10.1534/genetics.107.084251

Nordrum, S., Bakke-McKellep, a M., Krogdahl, a, Buddington, R.K., 2000. Effects of soybean meal and salinity on intestinal transport of nutrients in Atlantic salmon (Salmo salar L.) and rainbow trout (Oncorhynchus mykiss). Comp. Biochem. Physiol. B. Biochem. Mol. Biol. 125, 317-35.

Palkovacs, E.P., Marshall, M.C., Lamphere, B.A., Lynch, B.R., Weese, D.J., Fraser, D.F., Reznick, D.N., Pringle, C.M., Kinnison, M.T., 2009. Experimental evaluation of evolution and coevolution as agents of ecosystem change in Trinidadian streams. Philos. Trans. R. Soc. Lond. B. Biol. Sci. 364, 1617-28. doi:10.1098/rstb.2009.0016

Parks, D.H., Tyson, G.W., Hugenholtz, P., Beiko, R.G., 2014. STAMP: statistical analysis of taxonomic and functional profiles 30, 3123-3124. doi:10.1093/bioinformatics/btu494

Pérez, T., Balcázar, J.L., Ruiz-Zarzuela, I., Halaihel, N., Vendrell, D., de Blas, I., Múzquiz, J.L., 2010. Host-microbiota interactions within the fish intestinal ecosystem. Mucosal Immunol. 3, 355-360. doi:10.1038/mi.2010.12 
Roeselers, G., Mittge, E.K., Stephens, W.Z., Parichy, D.M., Cavanaugh, C.M., Guillemin, K., Rawls, J.F., 2011. Evidence for a core gut microbiota in the zebrafish. ISME J. 5, 1595-608. doi:10.1038/ismej.2011.38

Rumpold, B.A., Schlüter, O.K., 2013. Potential and challenges of insects as an innovative source for food and feed production. Innov. Food Sci. Emerg. Technol. 17, 1-11. doi:10.1016/j.ifset.2012.11.005

Sakai, M., 1999. Current research status of fish immunostimulants. Aquaculture 172, 63-92. doi:10.1016/S0044-8486(98)00436-0

Salipante, S.J., Sengupta, D.J., Rosenthal, C., Costa, G., Spangler, J., Sims, E.H., Jacobs, M. a, Miller, S.I., Hoogestraat, D.R., Cookson, B.T., McCoy, C., Matsen, F. a, Shendure, J., Lee, C.C., Harkins, T.T., Hoffman, N.G., 2013. Rapid $16 S$ rRNA next-generation sequencing of polymicrobial clinical samples for diagnosis of complex bacterial infections. PLoS One 8, e65226. doi:10.1371/journal.pone.0065226

Sánchez-Muros, M.J., Barroso, F.G., Manzano-Agugliaro, F., 2014. Insect meal as renewable source of food for animal feeding: A review. J. Clean. Prod. doi:10.1016/j.jclepro.2013.11.068

Schmid, C., Araki, H., 2010. Is hatchery stocking a help or harm? Aquaculture 308, 102 
S2-S11. doi:10.1016/j.aquaculture.2010.05.036

Semova, I., Carten, J.D., Stombaugh, J., MacKey, L.C., Knight, R., Farber, S.A., Rawls, J.F., 2012. Microbiota regulate intestinal absorption and metabolism of fatty acids in the zebrafish. Cell Host Microbe 12, 277-288. doi:10.1016/j.chom.2012.08.003

Storebakken, T., Baeverfjord, G., Lein, I., Roem, A.J., 2000. Differing nutritional responses to dietary soybean meal in rainbow trout ž Oncorhynchus mykiss / and Atlantic salmon ž Salmo salar / q. Aquaculture 190, 49-63.

Sullam, K.E., Essinger, S.D., Lozupone, C.A., O'Connor, M.P., Rosen, G.L., Knight, R., Kilham, S.S., Russell, J.A., 2012. Environmental and ecological factors that shape the gut bacterial communities of fish: A meta-analysis. Mol. Ecol. 21, 3363-3378. doi:10.1111/j.1365-294X.2012.05552.x

Sullam, K.E., Rubin, B.E., Dalton, C.M., Kilham, S.S., Flecker, A.S., Russell, J.A., 2015. Divergence across diet, time and populations rules out parallel evolution in the gut microbiomes of Trinidadian guppies. ISME J. 9, 15081522. doi:10.1038/ismej.2014.231

Thompson, J.N., 1994. The coevolutionary process. University of Chicago Press.

Tipping, J., 1998. Return rates of hatchery-produced sea-run cutthroat trout reared 103 
in a pond versus a standard or baffled raceway. Progress. fish-culturist 109113. doi:10.1577/1548-8640(1998)060<0109

Urke, H.A., Koksvik, J., Arnekleiv, J. V., Hindar, K., Kroglund, F., Kristensen, T., 2010. Seawater tolerance in Atlantic salmon, Salmo salar L., brown trout, Salmo trutta L., and S. salar $\times$ S. trutta hybrids smolt. Fish Physiol. Biochem. 36, 845-853. doi:10.1007/s10695-009-9359-x

Utter, F., Campton, D., Grant, S., Milner, V., Seeb, J., Wishard, L., 1980. Population structures of indigenous salmonid species of the Pacific Northwest, in: McNeil, W.J., Himsworth, D.C. (Eds.), Salmonid Ecosystems of the North Pacific. Oregon State University Press, Corvallis, OR, pp. 285-304.

Utter, F.M., Allendorf, F.W., 1994. Society for Conservation Biology Phylogenetic Relationships Among Species of Oncorhynchus: A Consensus View. Source Conserv. Biol. 8, 864-867.

Vahedi, G., Ghodratizadeh, S., 2011. Effect of Chitin Supplemented Diet on Innate Immune Response of Rainbow Trout. World J. Fish Mar. Sci. 3, 509-513.

Vermeij, G. 1, 1994. The Evolutionary Interaction among Species: Selection, Escalation and Coevolution. Annu. Rev. Ecol. Syst 25, 219-36.

Verschuere, L., Rombaut, G., 2000. Probiotic bacteria as biological control agents 104 
in aquaculture. ... Mol. Biol. ... 64 . doi:10.1128/MMBR.64.4.655671.2000.Updated

Wesolowska-Anderson, et al., 2014. Choice of bacterial DNA extraction method from fecal material influences community structure as evaluated by metagenomic analysis. Microbiome 2, 19. doi:10.1186/2049-2618-2-19

Wilson, J.M., Bunte, R.M., Carty, A.J., 2009. Evaluation of rapid cooling and tricaine methanesulfonate (MS222) as methods of euthanasia in zebrafish (Danio rerio). J. Am. Assoc. Lab. Anim. Sci. 48, 785-9.

Wong, S., Waldrop, T., Summerfelt, S., Davidson, J., Barrows, F., Kenney, B.B., Welch, T., Wiens, G.D., Snekvi, K., Rawls, J.F., Good, C., 2013. Aquacultured rainbow trout (Oncorhynchus mykiss) possess a large core intestinal microbiota that is resistant to variation in diet and rearing density. Appl. Environ. Microbiol. 79, 4974-4984. doi:10.1128/AEM.00924-13

Xia, J.H., Lin, G., Fu, G.H., Wan, Z.Y., Lee, M., Wang, L., Liu, X.J., Yue, G.H., 2014. The intestinal microbiome of fish under starvation. BMC Genomics 15, 266. doi:10.1186/1471-2164-15-266

Zhou, S., Xu, R., He, F., Zhou, J., Wang, Y., Zhou, J., Wang, M., Zhou, W., 2016. Diversity of gut microbiota metabolic pathways in 10 pairs of Chinese infant 
twins. PLoS One 11, e0161627. doi:10.1371/journal.pone.0161627

Zhu, L., Wu, Q., Dai, J., Zhang, S., Wei, F., 2011. Evidence of cellulose metabolism by the giant panda gut microbiome. Proc. Natl. Acad. Sci. U. S. A. 108, 177149. doi:10.1073/pnas.1017956108 


\section{Appendix}

Supplemental Files 
All supplemental files are Excel documents and must be opened through the Excel Program.

S1. 3432_total_OTUs.xml.............................................. 10MB

S2. all_taxa_phylum.xml................................................. 116B

S3. all_taxa_class.xml..................................................... 266

S4. all_taxa_order.xml.................................................... 483 KB

S5. all_taxa_family.xml.................................................... 933KB

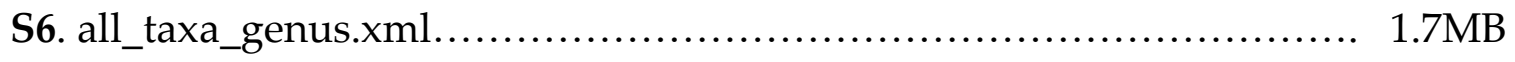

S7. all_taxa_species.xml................................................... $2 \mathrm{MB}$

S8. core_microbiota_east.xml................................................ 38K

S9. core_microbiota_west.xml......................................... 14KB 